\title{
مؤشرات الربكية المصرفية وانغكاساتها على الاستثمار لعينة من المصارف التجارية المدرجة في هيئة الاوراق المالية العراقية
}

\author{
أسعد حمدي محمد ماهر و حارث حامد احمد الجاف \\ قسم العلوم المالية والمصرفية، كلية الأدارة والأقتصاد، جامعة التنمية البشرية، السليمنية،اقليم كوردستان، العراق
}

ذاته ،اي انه بهتم حصرا بالعوائد والتكاليف من وجهة نظر المشروع فقط ، وجوهر هذا

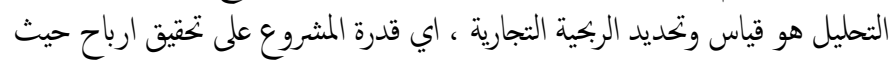

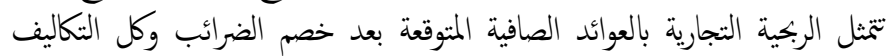

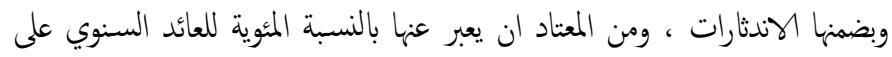

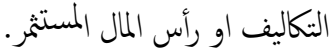

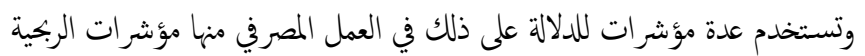

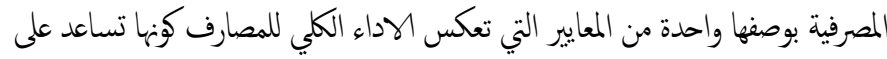

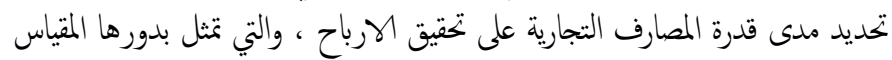

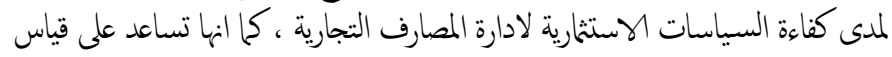

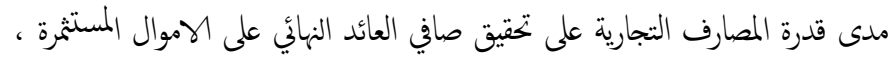

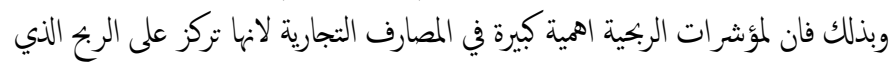

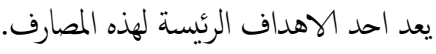

\section{اولا : مشكلة البحث}

تعد مؤشرات الربحية المصرفية من اهم مؤشرات الهاداء المالي في المصارف التجارية

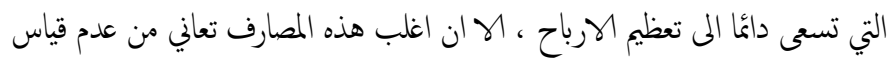

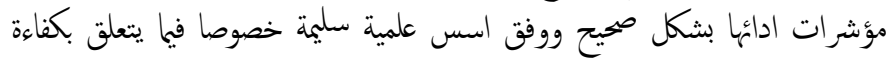

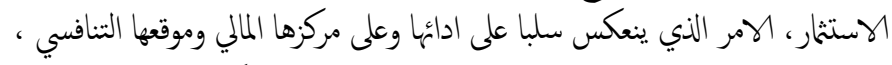

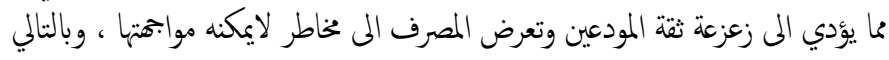

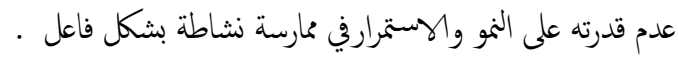

ثانيا : اهمية البحث

تتجلى اهمية البحث بحيوية الموضوع الذي يتناول عينة من المصارف التجارية في

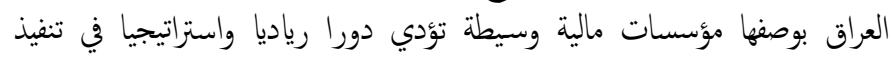

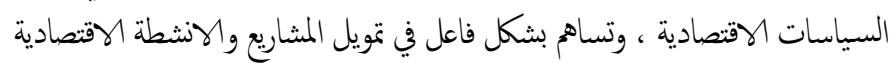

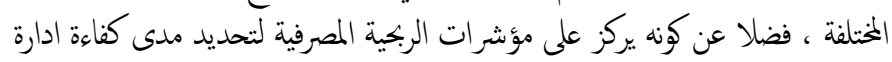

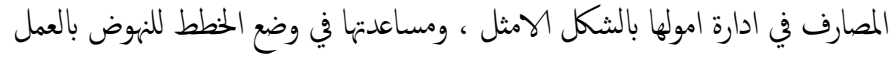

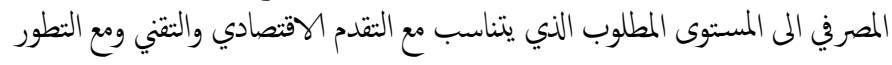

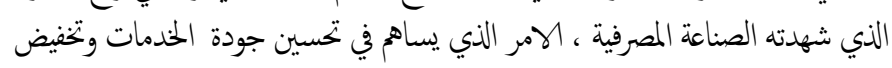

المستخلص- تعد مؤشرات الرجية المصرفية بمثابة الوسيلة التي تمكن رجال الوعال

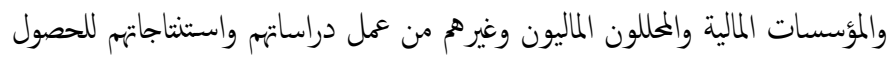

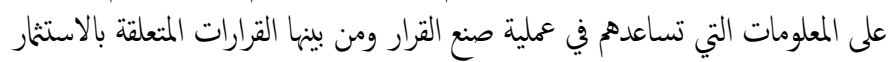

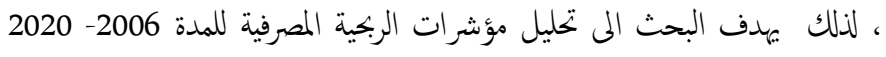

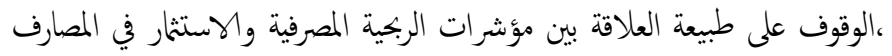

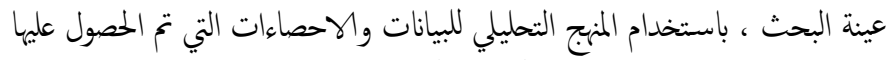

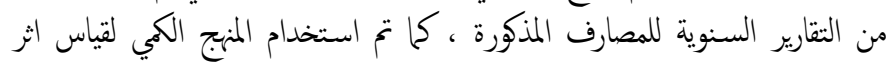

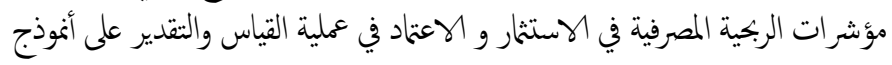

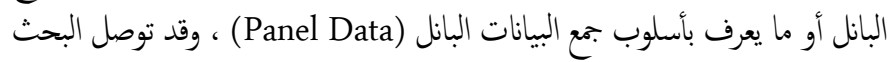

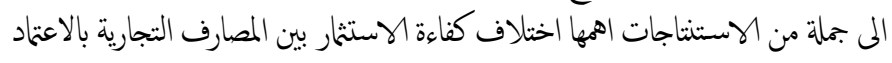

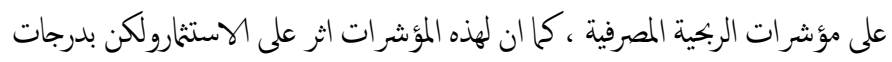

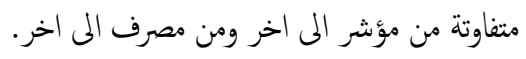
الكلمات الدالة- الاستثمار ، الربية المصرفية ، المصارف التجارية.

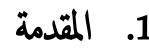

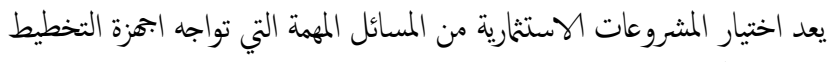

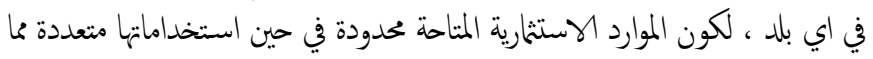

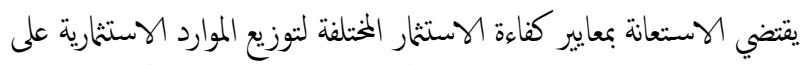

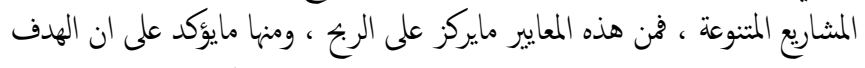

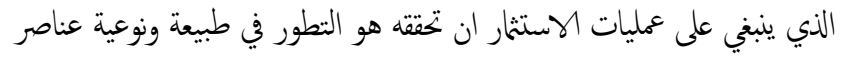

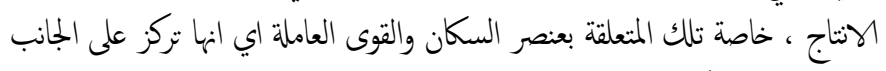

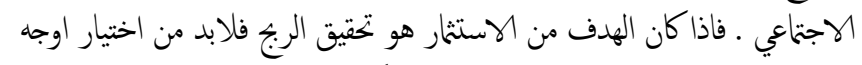

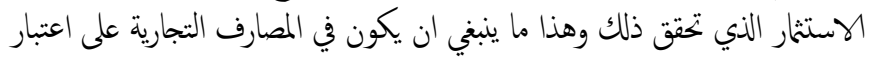
ان الربح احد اهدافها الرئيسة.

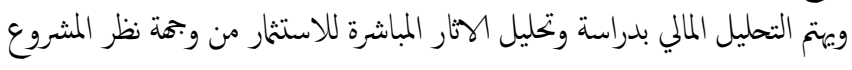




\begin{tabular}{|c|c|c|}
\hline 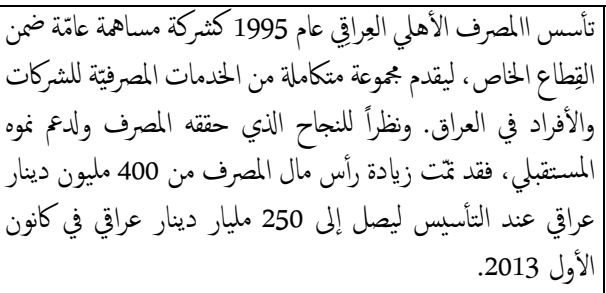 & المصرف الاهلي & 3 \\
\hline 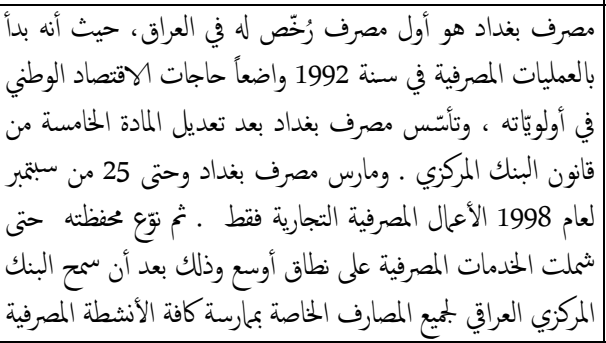 & مصرف بغداد & 4 \\
\hline 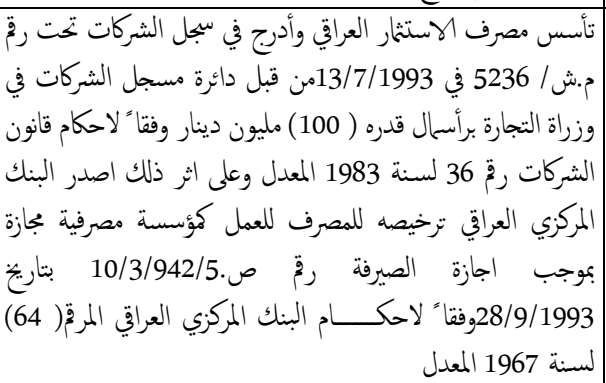 & مصرف الاستثمار & 5 \\
\hline
\end{tabular}

الحدود الزمانية : تح تحديد مدة البحث ب(2006 - 2020 ) وذلك لتوفر البيانات التي تخص البحث خلال هذه المدة

\section{سابعا :هيكل البحث}

من اجل التوصل المى هدف البحث والتحقق من فرضيته ، تح تقسيمه الى مبحثين :

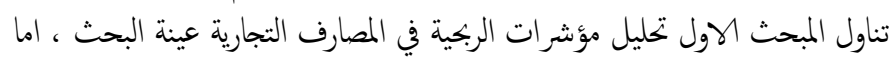

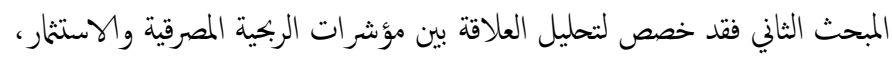

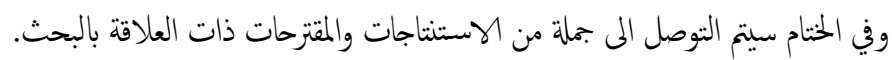

\section{المبحث الاول}

\section{تحليل مؤثرات الربحية في المصارف التجارية عينة البحث}

يعد الرخ هدفا اساسيا لجميع المصارف التجارية وامرا ضروريا لبقائها واستمرارها وغاية

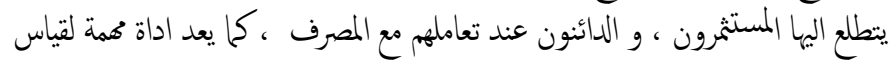

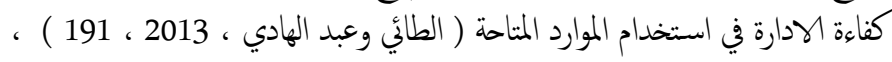
فهو مؤشر فعال في التعبير عن اداء المصرف وبذلك تعد مؤشرات الربكية من اهم اهم

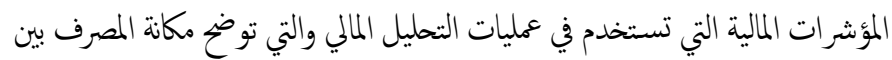

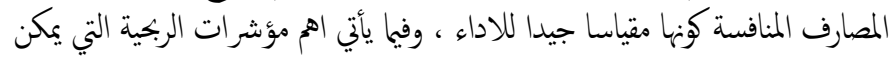

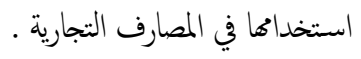

اولا: مؤشر صافي الريح

تحصل المنشآت على صافى الربح بعد تغطية كلف المبيعات ومصاريف التشغيل والفوائد والضرائب, ويشكل صافى الربح مؤشراً هاماً على قدرة الإدارة في تسيير أنشطة
التكليف مما ينعكس على تحقيق معدلات عالية من الارباح ، وتحقيق اهداف المصارف

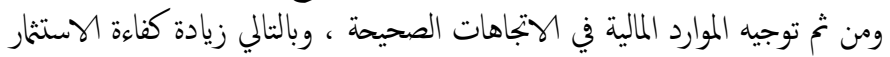

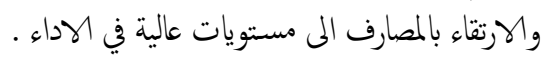

ثالثا : هدف البحث يسعى البحث المى تحقيق الهداف البحاف الاتية : 1- التعرف على انواع مؤشرات الربجية المصرفية

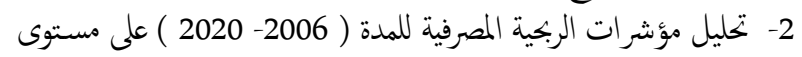
المصارف عينة البحث والمقارنة بينها . 3- الوقوف على طبيعة العلاقة بين مؤشرات الربحية المصرفية والاستثمار في لمعند

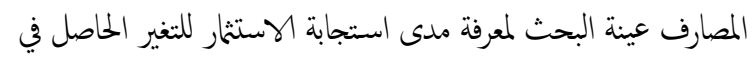

$$
\begin{aligned}
& \text { كل مؤشر على حدة. } \\
& \text { رابعا : فرضية البحث } \\
& \text { ينطلق البحث من الفرضيات الاتية : فرضيه البحت }
\end{aligned}
$$

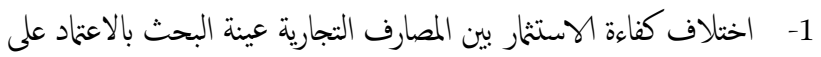

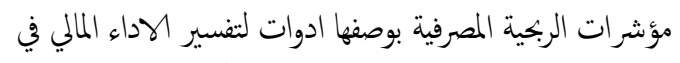

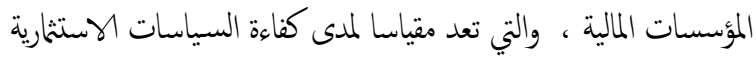

$$
\text { لادارة المصارف التجارية . }
$$

2- توجد علاقة ذات دلالة احصائية بين مؤشرات الربحية المصرفية والاستثمار

$$
\text { خامسا: منهج البحث المصارف عينة البحث ولكن بدرجات متفاوتة . }
$$

سيتم معالجة الموضوع وإتباع المنهج الوصفي التحليلي لكونه أسلوب من أساليب

\begin{tabular}{|c|c|c|}
\hline التعريف & اسم المصرف & ت \\
\hline 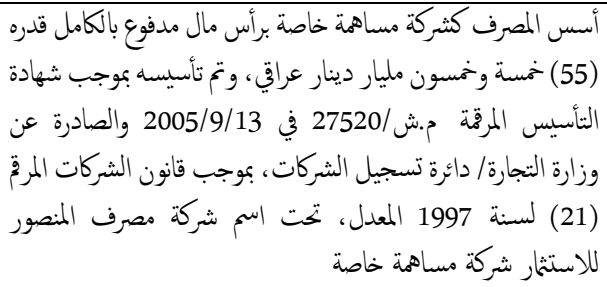 & مصرف المنصور & 1 \\
\hline 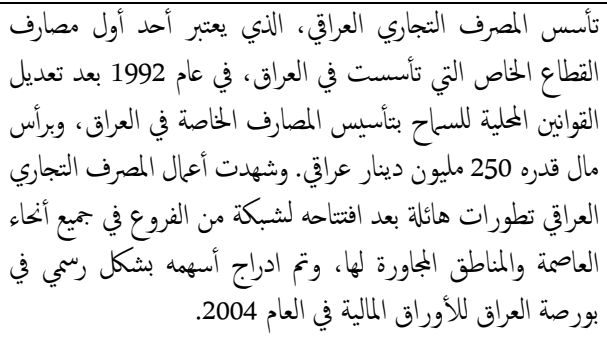 & المصرف التجاري & 2 \\
\hline
\end{tabular}

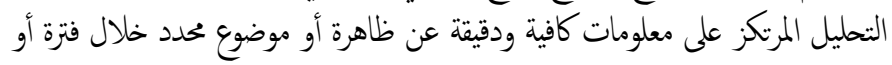

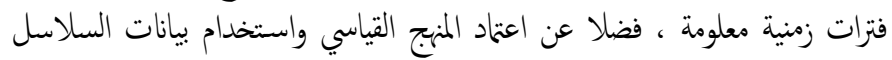

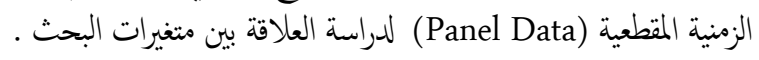

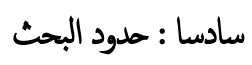

الحدود الملكانية : من اجل اجراء الدراسة التطبيقية تح اختيار خمسة مصارف تجارية من المصارف المدرجة في هيئة الاوراق المالية العراقية والتي لها فروع في اقلية اقليم كوردستان إندان و

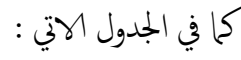


في عام 2016 إذ بلغت (64.2\%)، ويعود السبب في ذلك الى ان المصرف حقت

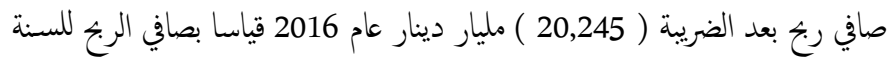

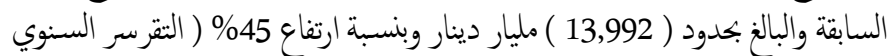

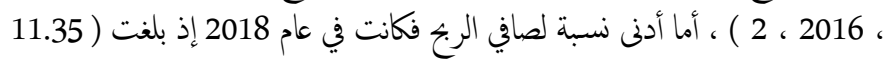

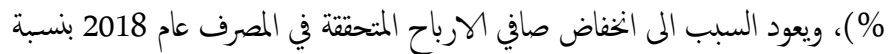

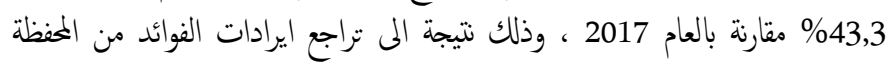

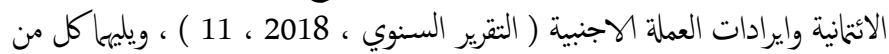

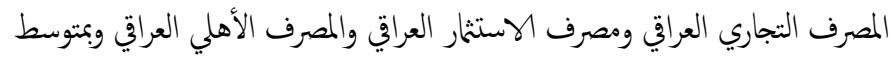

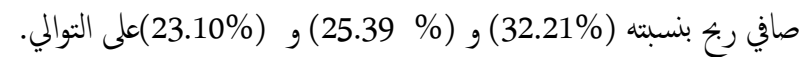
كما يتضح من قراءة نتائج الجدول، أن متوسط صافي الأرباح للمصارف عينة الدراسة

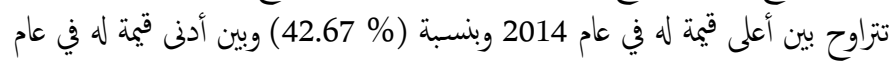

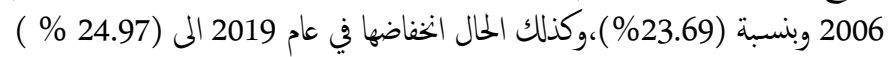

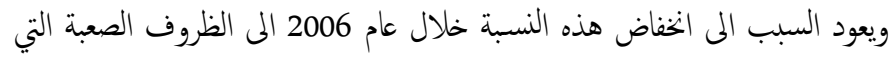

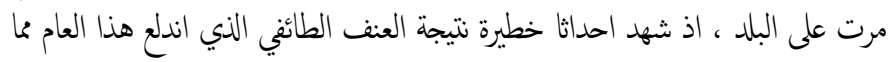

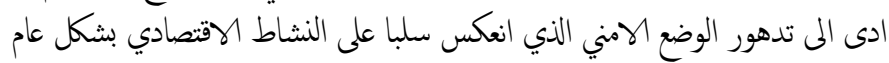

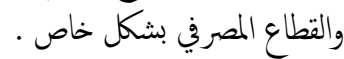

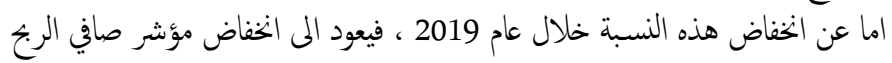

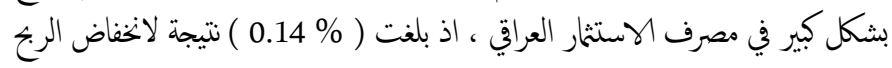

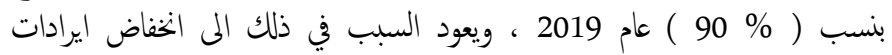

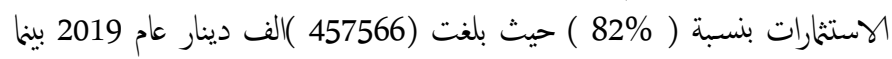
كانت ( 2570335 ) الف دينار عام 2018 ، و وكذلك انخفاض ايرادات العمولات

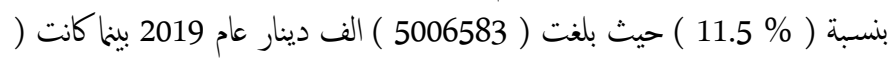
5654363 ) الف دينار عام 2018 ( التقرير السنوي ، 2019 ، 9 ( 9 ) .

ثانيا: معدل العائد على الاستثمار

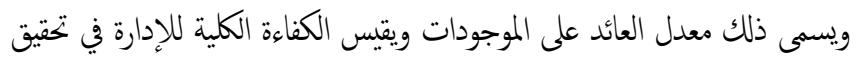

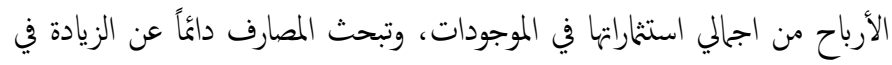

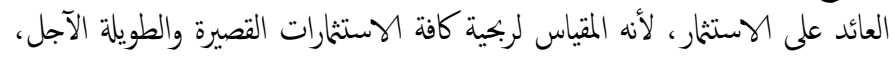

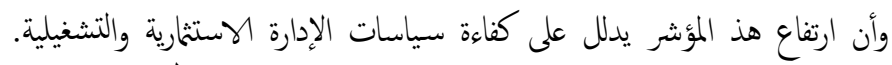

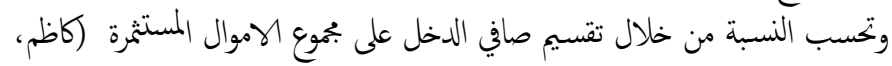

. (32 ، 2015

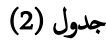

معدل العائد على الاستثار للمصارف عينة البحث للمدة (2006-2020)

(نسبة مثوية)

\begin{tabular}{|c|c|c|c|c|c|c|}
\hline المتوسط & الاستثمر & مغداد & للاستثمرر & الأهلي & المجاري المراقي & السنةة \\
\hline 3.73 & 1.38 & 9.87 & 4.52 & 1.41 & 1.46 & 2006 \\
\hline 6.62 & 6.22 & 10.24 & 11.94 & 3.60 & 1.09 & 2007 \\
\hline 6.01 & 6.55 & 9.86 & 9.63 & 2.46 & 1.55 & 2008 \\
\hline 5.78 & 8.20 & 9.68 & 5.67 & 2.96 & 2.4 & 2009 \\
\hline 7.75 & 11.09 & 10.55 & 4.3 & 2.88 & 9.93 & 2010 \\
\hline
\end{tabular}

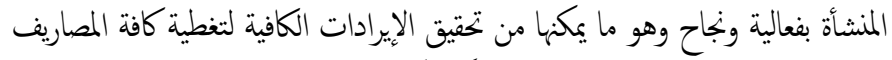

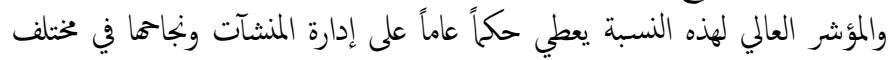

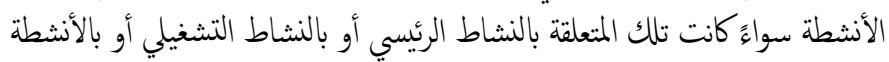

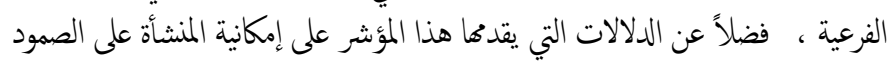

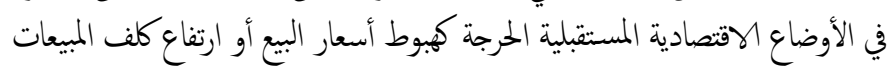

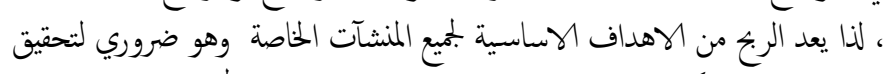

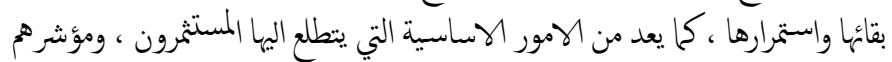

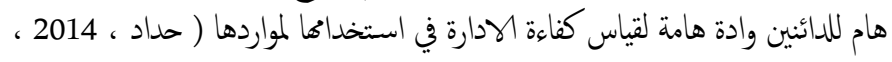
22 ) . ويستخرج مؤشر صافي الربح عن طريق قسمة صافى الريخ على الايرادات .

جدول (1)

مؤشر صافي الريح للمصارف عينة البحث للمدة (12006-2020)

(نسبة مثوية)

\begin{tabular}{|c|c|c|c|c|c|c|}
\hline المتوسط & الاستثمرف & مغداد & للاستثمر & الألصرف & المجاري & /المصرف \\
\hline 23.69 & 0.18 & 47.52 & 42.17 & 19.63 & 8.99 & 2006 \\
\hline 35.52 & 42.47 & 64.24 & 42.47 & 21.42 & 7.04 & 2007 \\
\hline 34.67 & 37 & 48.9 & 42.27 & 38.42 & 6.78 & 2008 \\
\hline 28.56 & 32.9 & 39.03 & 38.03 & 9.05 & 23.83 & 2009 \\
\hline 32.84 & 42.06 & 38.64 & 34.65 & 15.59 & 33.26 & 2010 \\
\hline 35.43 & 41.95 & 40.75 & 41.98 & 19.47 & 35.00 & 2011 \\
\hline 31.29 & 4.84 & 42.11 & 43.58 & 33.22 & 37.73 & 2012 \\
\hline 34.85 & 33.48 & 47.94 & 46.3 & 4.22 & 42.33 & 2013 \\
\hline 42.67 & 48.4 & 46.53 & 50.77 & 18.88 & 48.77 & 2014 \\
\hline 40.73 & 42.82 & 61.51 & 51.86 & 6.41 & 41.06 & 2015 \\
\hline 39.74 & 35.51 & 64.2 & 55.16 & 52.47 & 41.37 & 2016 \\
\hline 32.34 & 13.76 & 48.39 & 50.12 & 7.66 & 41.78 & 2017 \\
\hline 30.57 & 2.45 & 11.35 & 57.21 & 37.01 & 44.83 & 2018 \\
\hline 24.97 & 0.14 & 18.25 & 46.59 & 26.37 & 33.53 & 2019 \\
\hline 30.89 & 2.84 & 33.36 & 44.43 & 36.67 & 36.91 & 2020 \\
\hline 33.81 & 25.39 & 43.51 & 45.84 & 23.10 & 32.21 & المتوسط \\
\hline
\end{tabular}

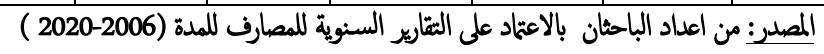

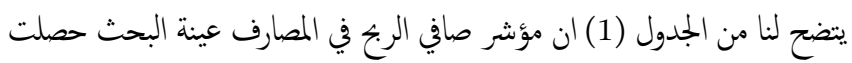

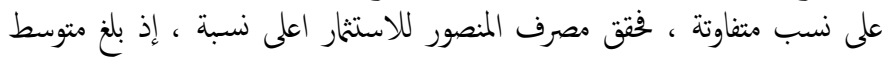

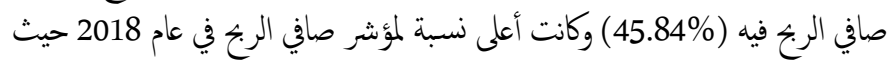

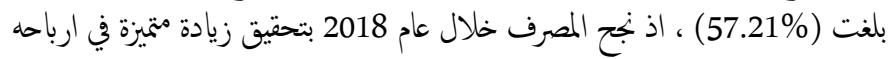

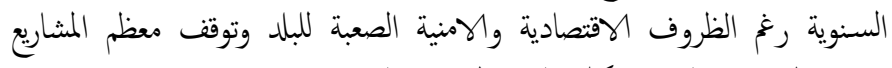

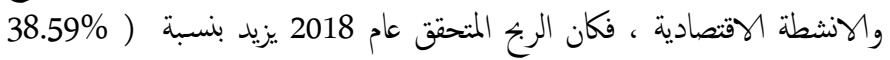

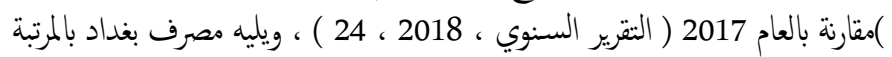

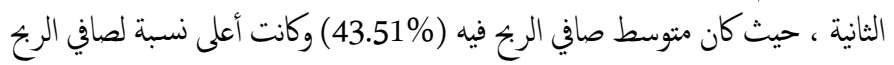


جدول (3) جينة

معدل العائد على حقوق الملكية للمصارف عينة البحث للمدة (2006-2020)

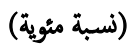

\begin{tabular}{|c|c|c|c|c|c|c|}
\hline المتوسط & الاستثمر & بغداد & للاستصور & المالمرافي & الماري العراقي & المصرف \\
\hline 4.63 & 0.07 & 14.13 & 4.49 & 2.81 & 1.68 & 2006 \\
\hline 5.23 & 2.81 & 2.6 & 12.76 & 5.66 & 2.32 & 2007 \\
\hline 11.36 & 7.17 & 22.9 & 14.09 & 10.08 & 2.6 & 2008 \\
\hline 6.57 & 7.34 & 14.47 & 5.37 & 1.13 & 4.55 & 2009 \\
\hline 8.41 & 10.06 & 11.51 & 4.33 & 2.15 & 14.03 & 2010 \\
\hline 7.67 & 8.46 & 15.01 & 7.22 & 2.36 & 5.31 & 2011 \\
\hline 7.41 & 1.16 & 12.11 & 4.64 & 9.96 & 9.22 & 2012 \\
\hline 9.43 & 14.38 & 11.01 & 9.02 & 8.23 & 4.51 & 2013 \\
\hline 6.31 & 10.17 & 9.5 & 6 & 2.67 & 3.24 & 2014 \\
\hline 5.05 & 6.25 & 8.56 & 6.84 & 0.91 & 2.68 & 2015 \\
\hline 5.09 & 3.51 & 6.16 & 5 & 8.16 & 2.63 & 2016 \\
\hline 2.55 & 1.05 & 2.21 & 5.11 & 1 & 3.4 & 2017 \\
\hline 3.41 & 1.1 & 1.93 & 7.11 & 3.09 & 3.81 & 2018 \\
\hline 2.33 & 0.06 & 2.68 & 2.96 & 3.55 & 2.41 & 2019 \\
\hline 7.65 & 10.61 & 7.25 & 2.44 & 6.45 & 11.52 & 2020 \\
\hline 6.13 & 5.62 & 9.46 & 6.49 & 4.54 & 4.92 & المتوسط \\
\hline
\end{tabular}

المصدر: من اعداد الباحثان بالاعتاد على الثقارير السنوية للمصارف المدة (2006-2020 )

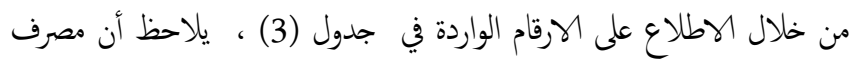

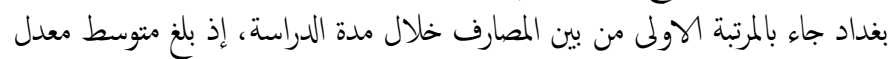

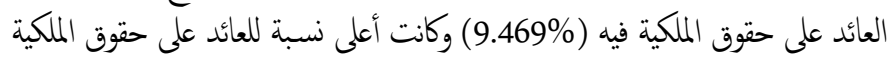

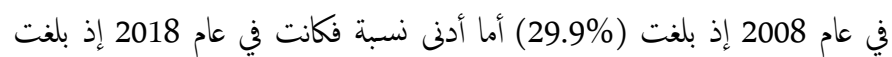
(1.93\%)، ويعود سبب انخفاض هذه النسبة الى الخفاض الايرادات المتحققة خلال

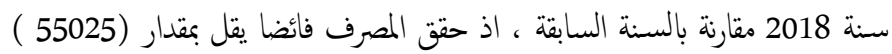
الف دينارعن سنة 2017 ( التقرير السنوي ، 2018 ، 3 ) ). و يليه في المرتبة المبانة الثانية

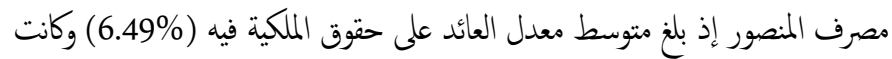

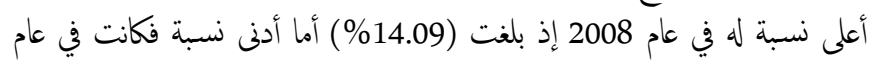

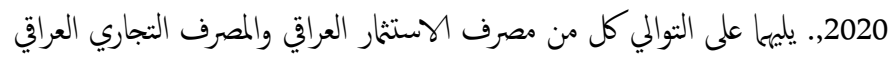

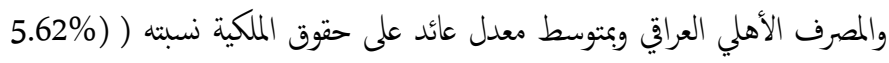
(4.54\%) (4.92\%) على التوالي.

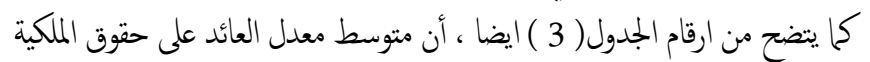

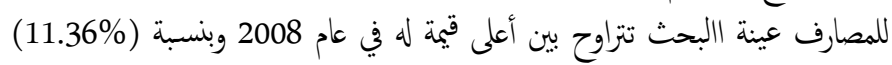

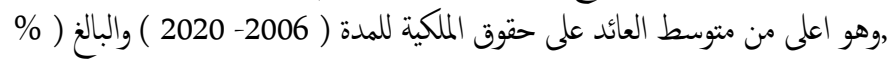

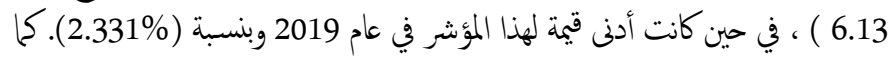

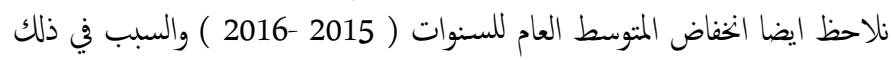

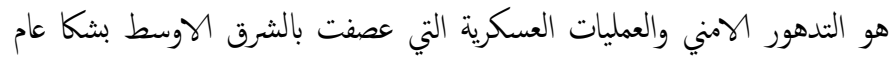

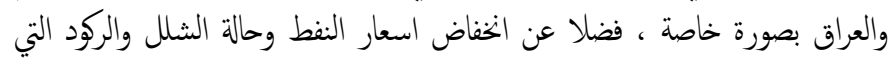

\begin{tabular}{|c|c|c|c|c|c|c|}
\hline 5.11 & 3.08 & 12.22 & 2.78 & 1.27 & 6.22 & 2011 \\
\hline 7.23 & 5.93 & 10.49 & 5.0 & 4.41 & 10.36 & 2012 \\
\hline 7.44 & 6.30 & 7.81 & 6.53 & 8.68 & 7.86 & 2013 \\
\hline 5.68 & 7.61 & 6.1 & 3.72 & 7.69 & 3.28 & 2014 \\
\hline 6.98 & 10.33 & 8.6 & 3.19 & 9.64 & 3.18 & 2015 \\
\hline 5.66 & 4.08 & 7.78 & 3.75 & 10.8 & 1.9 & 2016 \\
\hline 3.59 & 1.62 & 6.52 & 4.83 & 1.85 & 3.12 & 2017 \\
\hline 5.09 & 1.3 & 6.45 & 8.48 & 5.19 & 4.04 & 2018 \\
\hline 3.92 & 0.38 & 7.12 & 7.43 & 1.21 & 3.44 & 2019 \\
\hline 7,73 & 1.06 & 9.98 & 6.34 & 2.39 & 18.92 & 2020 \\
\hline 5.87 & 4.32 & 8.85 & 5.87 & 4.43 & 5.25 & L الم.92 \\
\hline
\end{tabular}

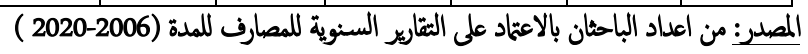

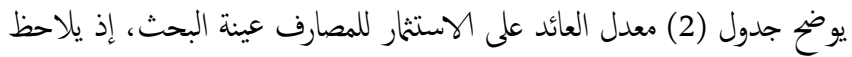

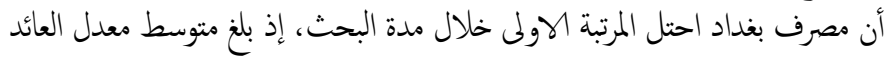

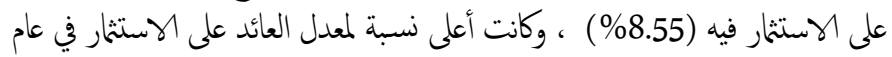

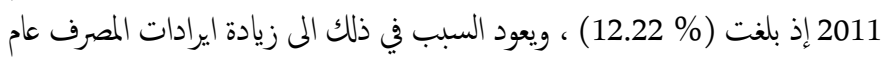

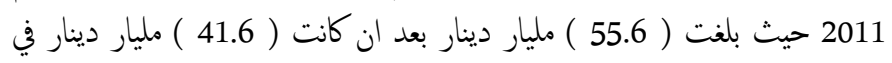

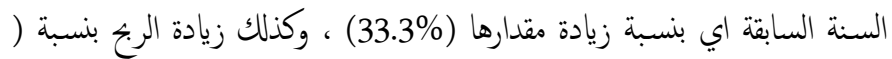

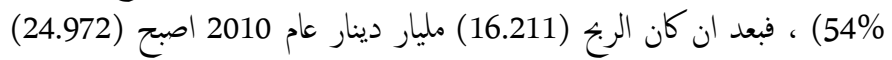

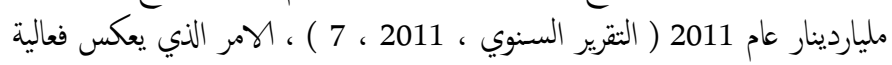

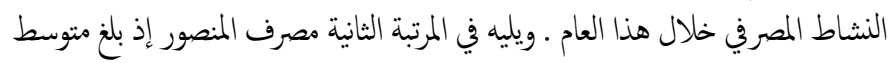

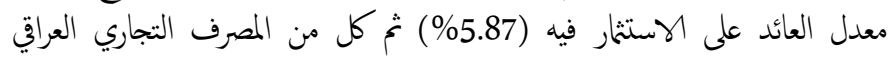

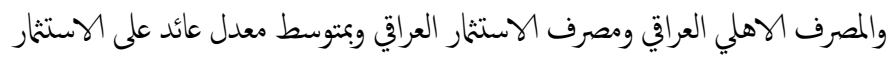
نسبته (5.25\%) (4.43\%) (4.32\%) على التوالي.

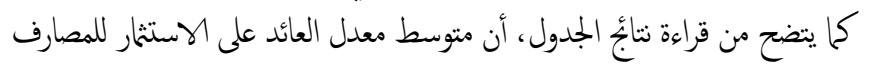

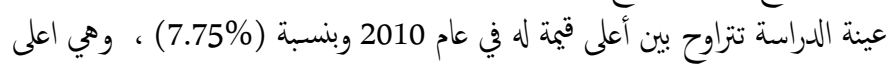

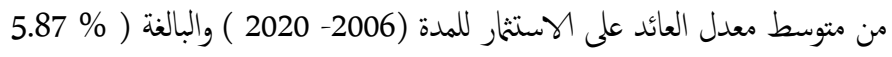

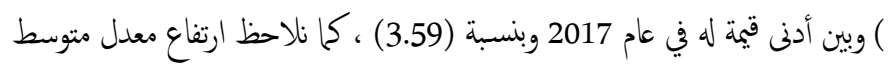

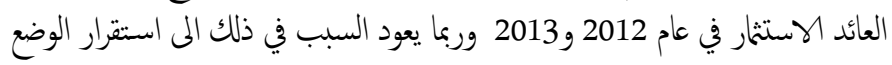

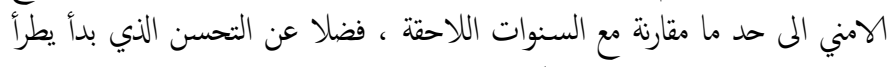

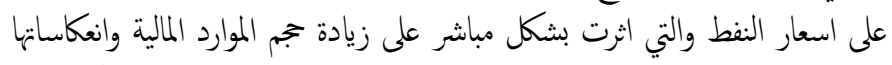

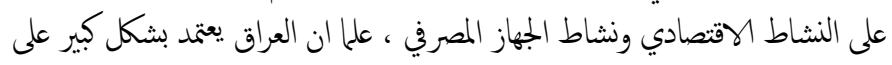
واردات النفط في تمويل موازنته .

\section{ثالثا: العائد على حقوق الملكية}

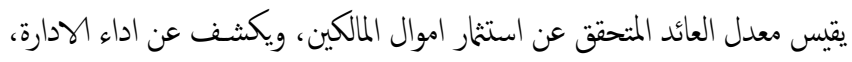

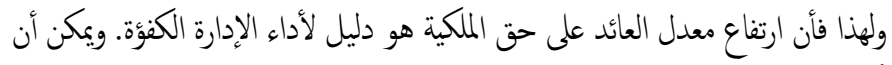

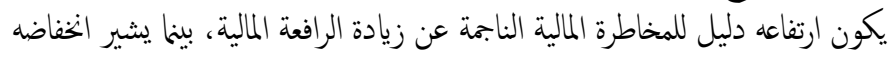

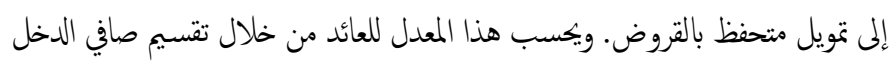

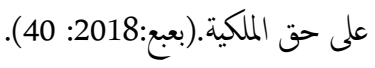


الاستثمار العراقي والمصرف الأهلي العراقي وبمتوسط معدل عائد على الودائع نسبته (5.34) (5.3\%) (7.34\%) (5.20\%) (4.93\%) على التوالي.

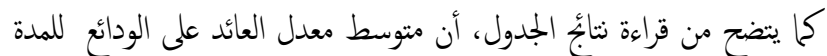

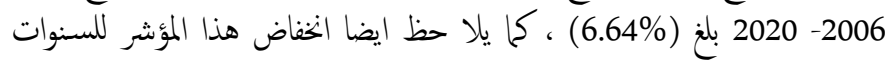

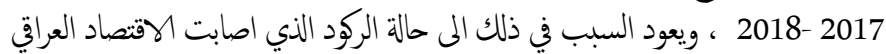

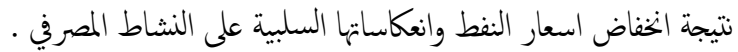

\section{خامساً: مؤشر معدل العائد على الاموال المتاحة}

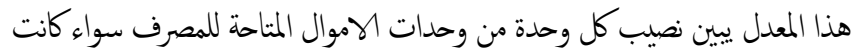

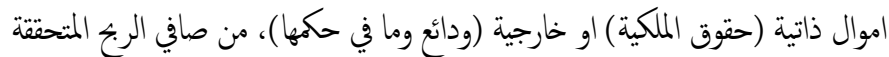

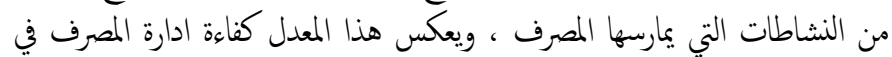

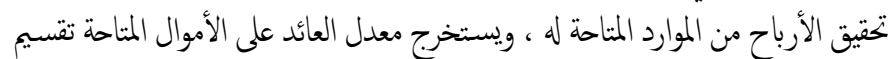

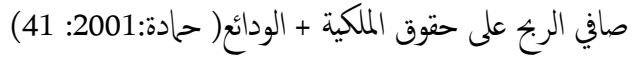

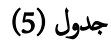

معدل العائد على الأموال المتاحة للمصارف عينة البحث للمدة (2006-2020)

(نسبة مثوية)

\begin{tabular}{|c|c|c|c|c|c|c|}
\hline المتوسط & الاستثمار & مغداد & للاستثمرر & الألملي & المجاري المراقي & |ل/ السمرف \\
\hline 1.91 & 2.78 & 4.18 & 0.01 & 1.86 & 0.75 & 2006 \\
\hline 4.79 & 1.98 & 10.87 & 7.03 & 3.18 & 0.93 & 2007 \\
\hline 4.86 & 4.3 & 8.82 & 5.5 & 4.57 & 1.11 & 2008 \\
\hline 2.14 & 2.05 & 3.24 & 2.53 & 0.63 & 2.24 & 2009 \\
\hline 3.5 & 1.48 & 2.18 & 3.91 & 1.09 & 7.58 & 2010 \\
\hline 3.02 & 2.49 & 4.72 & 3.25 & 1.37 & 3.28 & 2011 \\
\hline 3.12 & 2.0 & 3.01 & 0.44 & 4.98 & 5.17 & 2012 \\
\hline 3.36 & 1.9 & 3.3 & 5.7 & 2.89 & 3.02 & 2013 \\
\hline 2.46 & 1.55 & 1.98 & 5.34 & 1.17 & 2.27 & 2014 \\
\hline 1.61 & 0.46 & 1.89 & 3.24 & 0.45 & 2.01 & 2015 \\
\hline 2.42 & 1.88 & 1.4 & 1.77 & 5.22 & 1.84 & 2016 \\
\hline 1.08 & 0.59 & 1.38 & 0.54 & 0.6 & 2.32 & 2017 \\
\hline 1.29 & 0.39 & 1.66 & 0.06 & 1.77 & 2.58 & 2018 \\
\hline 0.92 & 0.67 & 0.58 & 0.003 & 1.8 & 1.56 & 2019 \\
\hline 3.84 & 1.49 & 0.56 & 8.31 & 2.73 & 6.1 & 2020 \\
\hline 2.62 & 1.73 & 3.32 & 3.18 & 2.29 & 2.85 & المتوسط \\
\hline
\end{tabular}

المصدر: من اعداد الباحثان بالاعثاد على التقارير السنوية للمصارف للمدة (2006-2020 )

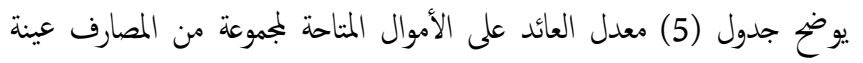

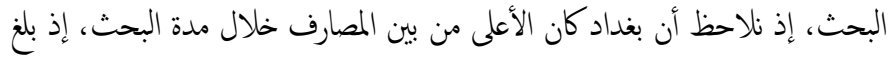

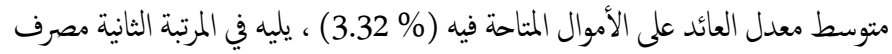

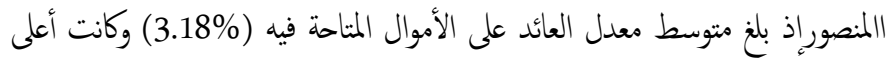

كادت ان تعصف بالاقتصاد العراقي واننكاساتها السلبية على النشاط المصرفي بشكل

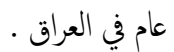

رابعاً: معدل العائد على الودائع يستخدم هذا المؤشر في قياس كفاءة المصرف في تولئ المعائ الأرباح من الودائع التي

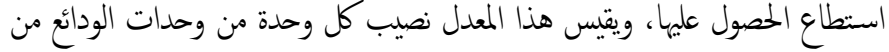

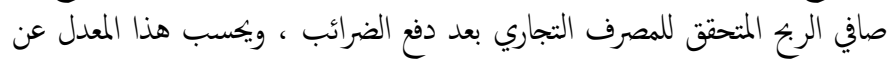

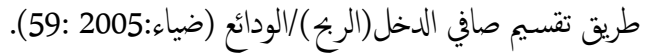

جدول (4) (4) - (ل)

معدل العائد على الودائع للمصارف عينة البحث للمدة (2006-2020)

(نسبة مثوية)

\begin{tabular}{|c|c|c|c|c|c|c|}
\hline المتوسط & الاستثار & مصدرف & للمصنصوف & الأملرف & الماراري & السنئرف \\
\hline 4.2 & 0.02 & 3.47 & 10.68 & 5.47 & 1.36 & 2006 \\
\hline 8.13 & 10.63 & 7.73 & 13.45 & 7.26 & 1.57 & 2007 \\
\hline 7.45 & 8.09 & 5.29 & 13.59 & 8.35 & 1.95 & 2008 \\
\hline 6.04 & 3.86 & 12.38 & 8.15 & 1.45 & 4.4 & 2009 \\
\hline 8.24 & 6.4 & 11.69 & 4.4 & 2.2 & 16.52 & 2010 \\
\hline 8.13 & 5.29 & 12.99 & 10.5 & 3.29 & 8.6 & 2011 \\
\hline 9.47 & 0.71 & 16.39 & 8.55 & 9.95 & 11.79 & 2012 \\
\hline 9.58 & 9.46 & 13.62 & 11.2 & 4.47 & 9.18 & 2013 \\
\hline 8.15 & 11.24 & 11.86 & 7.97 & 2.09 & 7.61 & 2014 \\
\hline 5.86 & 6.72 & 4.94 & 8.62 & 0.89 & 8.13 & 2015 \\
\hline 7.94 & 3.58 & 9.56 & 5.95 & 14.5 & 6.12 & 2016 \\
\hline 4.15 & 1.13 & 3.82 & 6.89 & 1.55 & 7.36 & 2017 \\
\hline 4.2 & 0.13 & 6.53 & 2.16 & 4.19 & 8.01 & 2018 \\
\hline 2.36 & 0.06 & 1.9 & 1.73 & 3.65 & 4.48 & 2019 \\
\hline 8.82 & 10.75 & 8.88 & 6.73 & 4.73 & 12.99 & 2020 \\
\hline 6.64 & 5.20 & 8.74 & 8.04 & 4.93 & 7.34 & المثوسط \\
\hline
\end{tabular}

المصدر: من اعداد الباحثان بالاعثاد على التقارير السنوية للمصارف للمدة (2006-2020 )

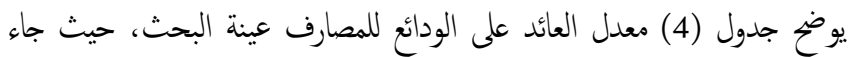

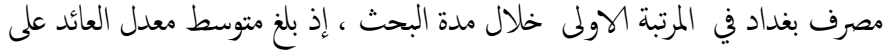

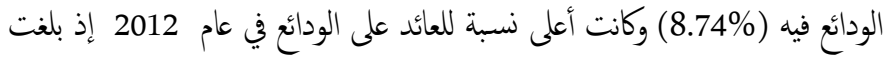

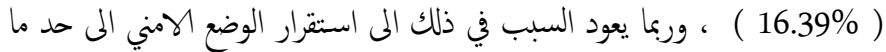

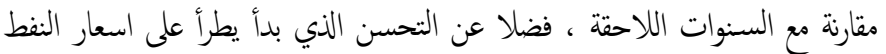

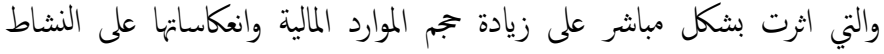

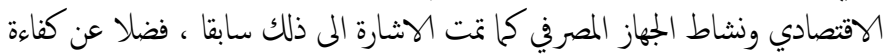

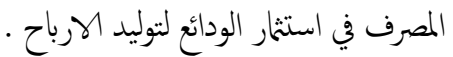
أما أدنى نسبة فكانت في عام 2019 إذ بلغت (1.9\%). ويليه في المرتبة الثانية

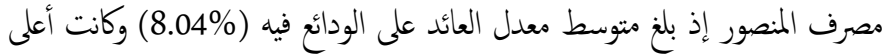

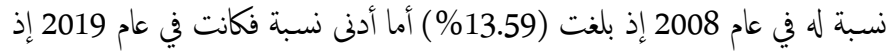

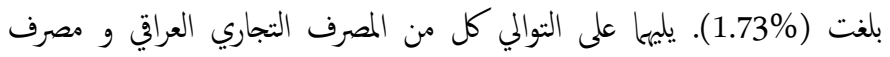


من خلال استقراء الارقام الواردة في الجدول (6) بخصوص معدل العائد على الأسهم

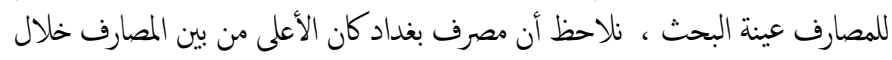

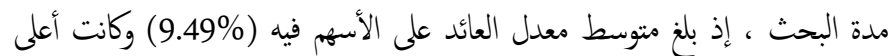

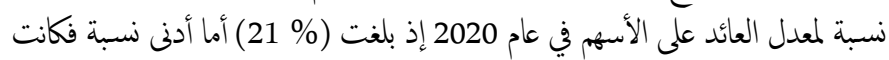

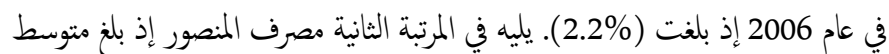

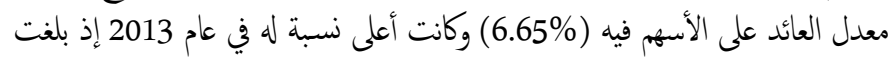

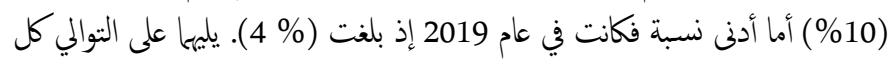

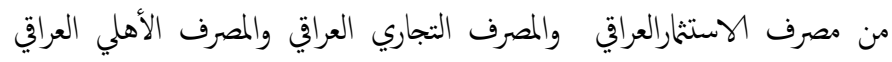

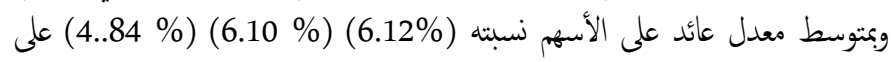
التوالي. كما يتضح من قراءة نتأُج الجدول، أن متوسط معدل العائد على الأسهم للمصارف

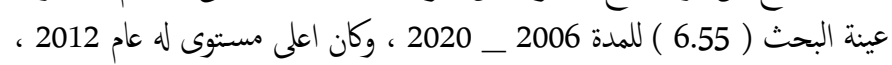

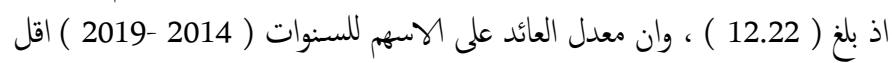

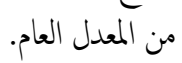

\section{المبحث الثاني}

\section{تحليل العلاقة بين مؤشرات الربجية المصرفية والاستمار}

يتناول هذا المبحث قياس وتحليل أثر مؤشرات الربحية المصرفية في الاستثمار للمدة

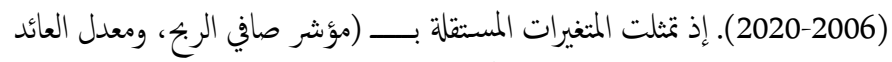

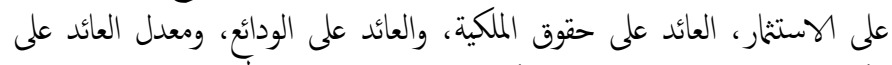

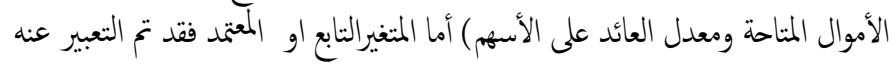

وان الأسلوب المستخدم في عملية القياس هو أسلوب بيانات السلاسل الزمنية المقطعية (Panel Data) أو ما تسمى بالبيانات الطولية (Longitudinal Data)

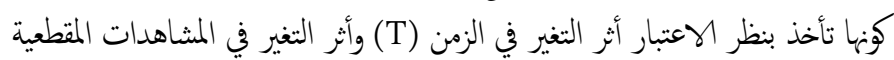

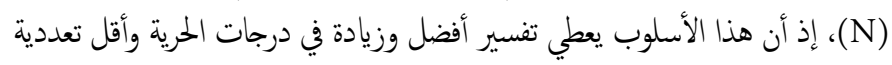

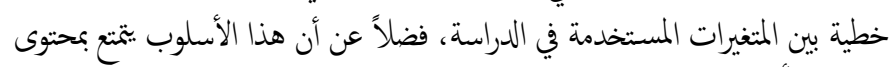

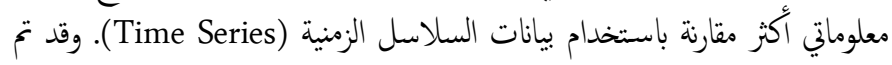

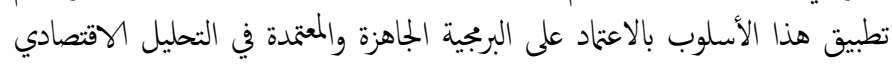
القياسي (Eviews-12). وعلية فأن الصيغة الرياضية للأنموذج ستكون بالشكل الآتي:

\section{$\mathrm{Y}=\boldsymbol{\beta}_{\mathrm{o}}+\boldsymbol{\beta}_{1} \mathrm{X}_{1}+\boldsymbol{\beta}_{2} \mathrm{X}_{2}+\boldsymbol{\beta}_{3} \mathrm{X}_{3}+\boldsymbol{\beta}_{4} \mathrm{X}+\boldsymbol{\beta}_{5} \mathrm{X}_{5}+\boldsymbol{\beta}_{6} \mathrm{X}_{6}$}

إذ T:

Y Y تمثل المثغير المعتمد، والذي يعبر عن الاستثار.

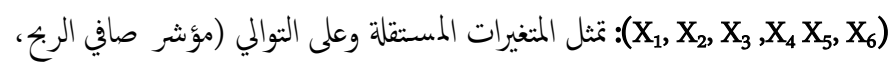

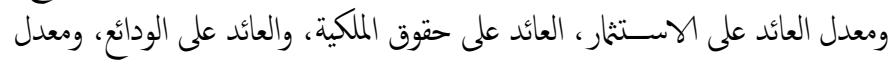
العائد على الأموال المتاحة ومعدل العائد على الأسهم). (الثابت) في الأموذج.

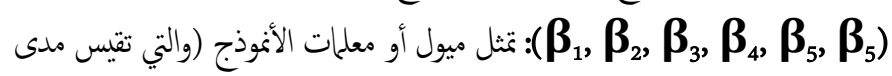
تأثير المتغيرات المستقلة في الاستثمر ).
نسبة له في عام 2020 إذ بلغت (8.31\%) أما أدنى نسبة فكانت في عام 2019 إذ إذ المبام

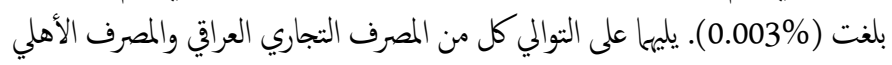

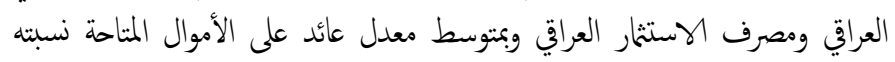
(2.29\%) ( 2.85\%)

كما يتضح من ق نتائُ الجدول (5 ) (2.85\% ) ايضا أن متوسط معدل العائد على الأموال

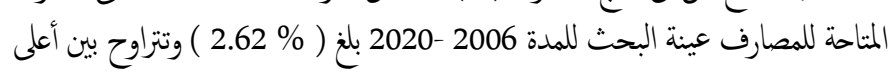
قيمة له في عام 2008 وبنسبة (4.86\%) وبين أدنى قيمة له في عام 2006 الم 2019 وبنسبة

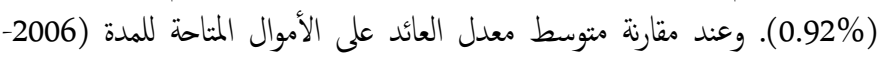

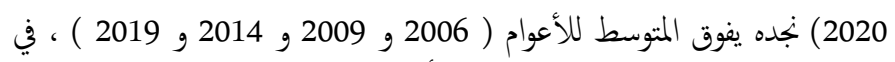

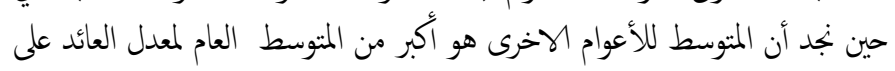

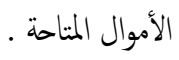

سادساً: معدل العائد على الاسهم

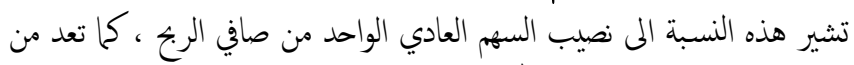

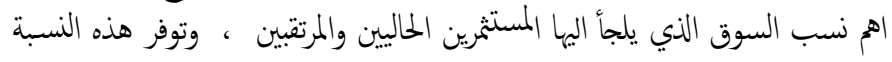

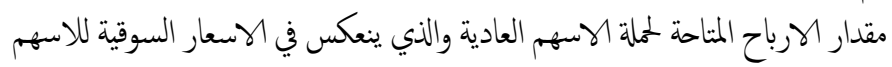

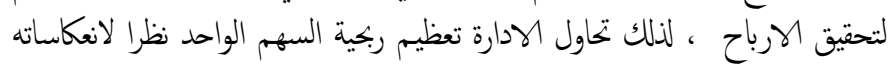

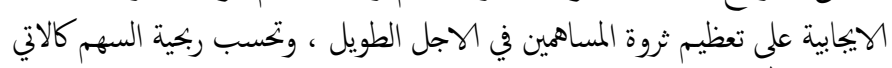

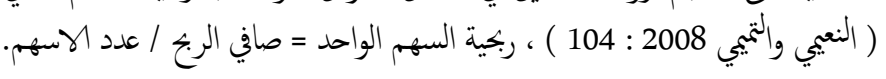

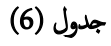

معدل العائد على الأسهم للمصارف عينة البحث للمدة (2006-2020)

(نسبة منوية)

\begin{tabular}{|c|c|c|c|c|c|c|}
\hline المتوسط & الاستثار & مصدرف & للمصترف & الألصرف & الماري العراقي & /لالمرف \\
\hline 4.32 & 5.7 & 2.2 & 7.1 & 3.7 & 2.7 & 2006 \\
\hline 4.78 & 9.1 & 3.2 & 7.2 & 2.5 & 1.9 & 2007 \\
\hline 4.5 & 5.1 & 2.7 & 7.0 & 3.5 & 4.2 & 2008 \\
\hline 8.46 & 9.1 & 18.6 & 5.8 & 2.4 & 6.4 & 2009 \\
\hline 10.98 & 11.9 & 13.7 & 4.9 & 2.3 & 22.1 & 2010 \\
\hline 9.02 & 9.0 & 19.0 & 7.9 & 2.0 & 7.2 & 2011 \\
\hline 12.22 & 14.0 & 14.0 & 4.9 & 15 & 13.2 & 2012 \\
\hline 11.04 & 17.3 & 13 & 10 & 9 & 5.9 & 2013 \\
\hline 5.12 & 1.1 & 11 & 6.8 & 3 & 3.7 & 2014 \\
\hline 3.23 & 1.57 & 2.3 & 7.9 & 1.1 & 3.3 & 2015 \\
\hline 4.46 & 0.78 & 3.3 & 5.8 & 9.4 & 3.03 & 2016 \\
\hline 3.42 & 0.78 & 2.4 & 5.9 & 4.0 & 4.02 & 2017 \\
\hline 4.64 & 1.2 & 6 & 7.2 & 3.4 & 5.4 & 2018 \\
\hline 5.22 & 2.7 & 10 & 4 & 6.1 & 3.3 & 2019 \\
\hline 8.28 & 2.5 & 21 & 7.4 & 5.3 & 5.2 & 2020 \\
\hline 6.55 & 6.12 & 9.49 & 6.65 & 4.84 & 6.10 & المتوسط \\
\hline
\end{tabular}

المصدر: من اعداد الباحثان بالاعثاد على التقارير السنوية للمصارف للمدة (2006-2020 ) 
يعد أنموذج الانحدار التجميعي من الناذج البســـيطة والســـهلة في تحليل بيانات

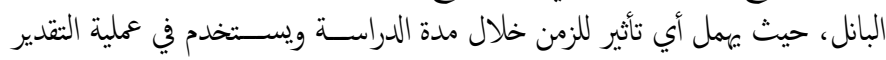

أنموذج طريقة المربعات الصغرى الاعتيادية (OLS).

\section{"أثموذج الأثر الثابت (Fixed Effect Model "FEM"):}

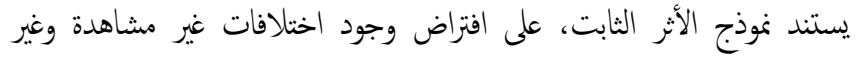

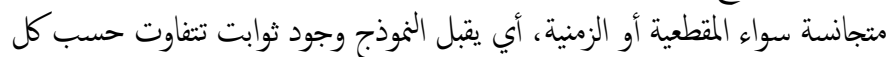

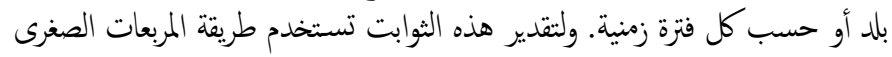

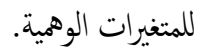

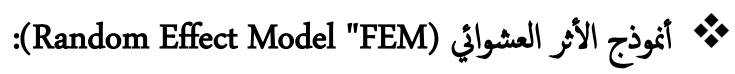
في أنموذج الأثر العشوائي يكون حد الخطأ (

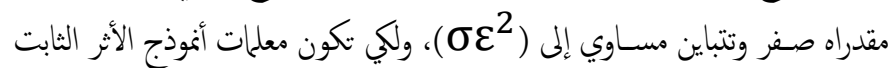

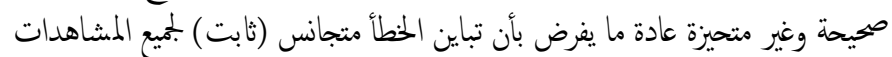
المقطعية وليس هناك أي ارتباط ذاتي خلال الزمن (الجمال، 2012، 272).

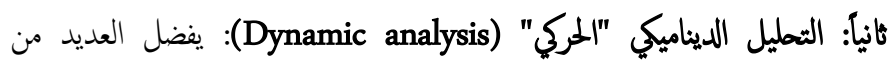

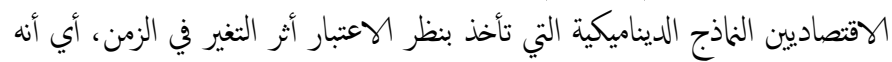

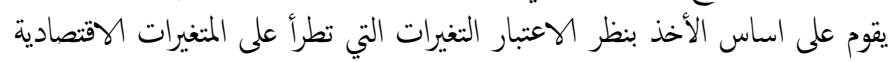

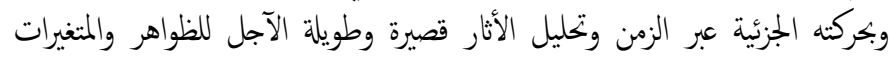

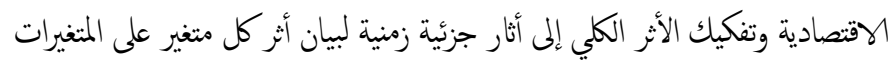

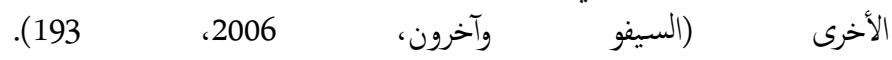
فني حالة تأثر كل من المتغير التابع والمتغيرات المستقلة في السنه الحالية بقيمها في

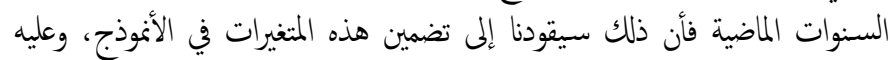

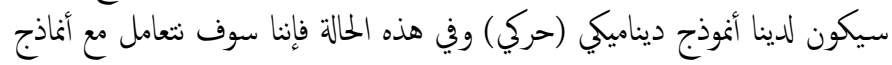

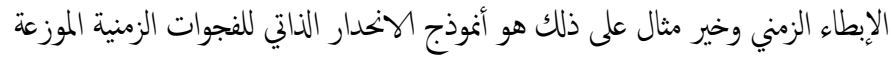
(Auto-regressive Distributed Lag Model) (Pesaran and Shin, 1999)

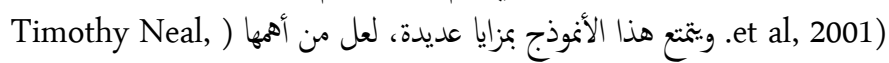

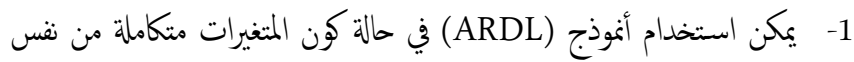

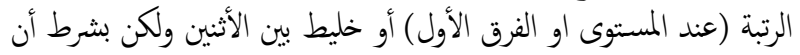
لا تاكون متكاملة من الدرجة الثانية.

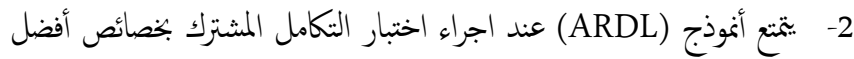

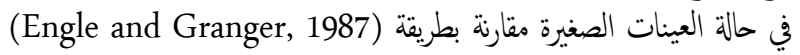

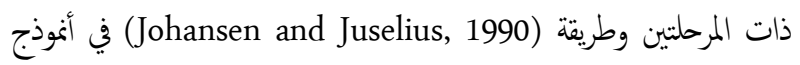
الانحدار الذاتي (Vector Auto-regression Model) والتي تنطلب أبجام كيرة للعينات.

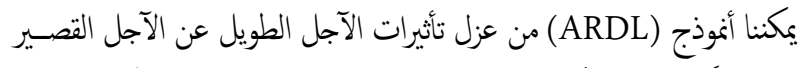

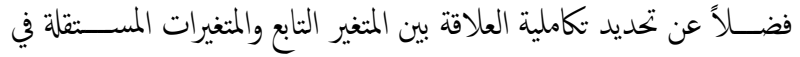

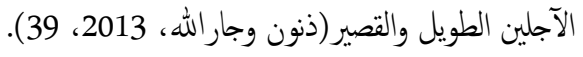

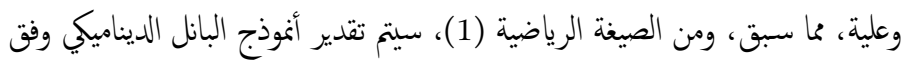

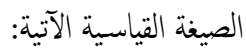

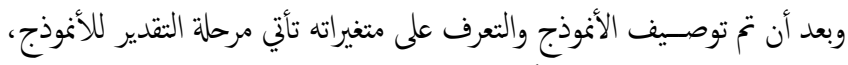

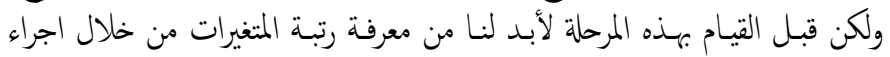

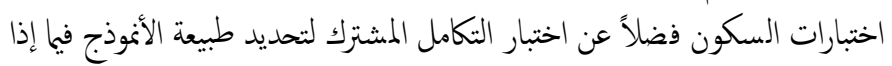
كان ساكناً أم متحركاً (ديناميكياً).

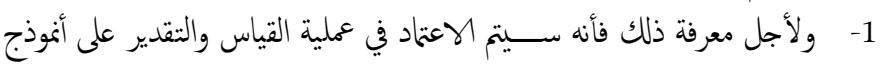

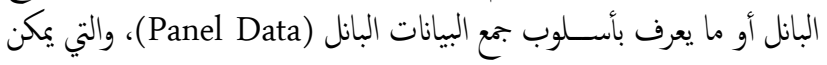

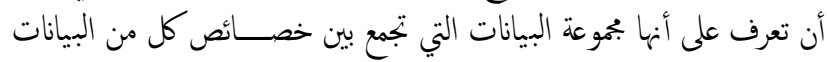

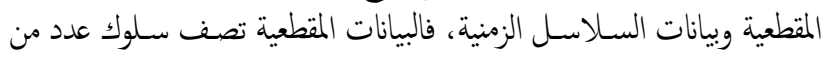

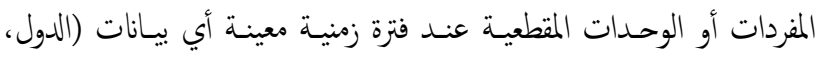

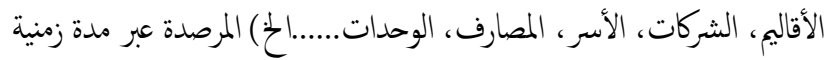

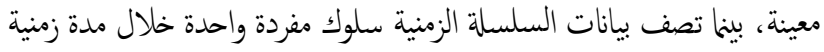

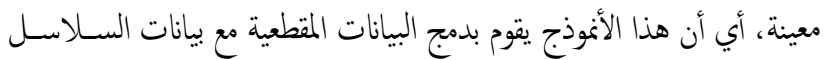

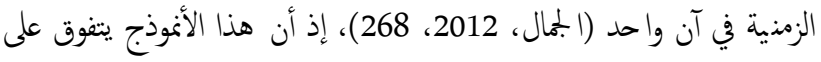
تحليل البيانات الزمنية والبيانات المقطعية بجملة من المزايا ، من أهمها:. (عطية، آندان

1- التحكم في التباين الفردي، الذي قد يظهر في حالة البيانات الزمنية أو المقطعية، والذي يؤدي إلى نتائُ متحيزة.

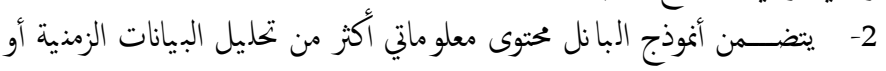

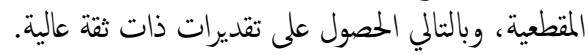

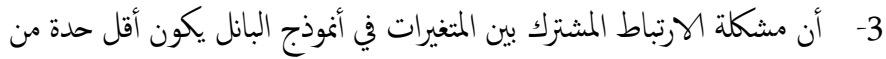
بيانات السلاسل الزمنية. 4- يتميز أثموذج البانل عن غيرها من الأنماذج والاساليب بدرجات حرية أكبر وكفاءة أفضل.

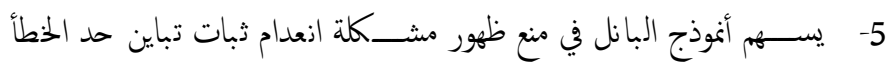
(Heteroscedasticity) الألماذج القياسية

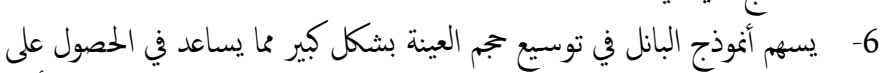

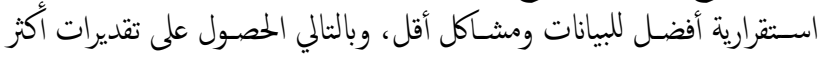
كفاءة. 7- أن حذف بعض المتغيرات قد يســبـ تحيز المقدرات للمعلمات الأصــلية في

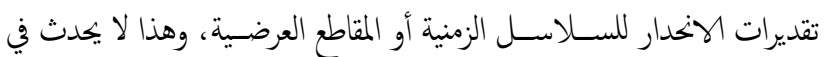

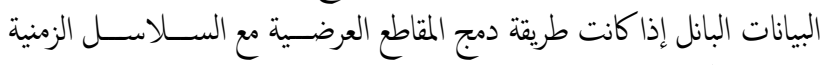

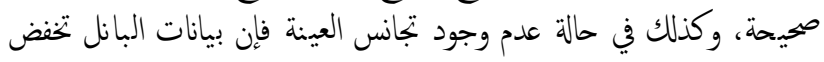

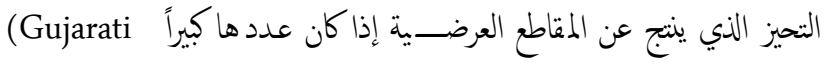
.2003, 37-38)

وهنا لابد من التميز بين نوعين من التحليل القياسي في أنموذج البانل ، وها: أولاً: التحليل الساكن (Static analysis): وهو التحليل الذي لا يأخذ بنظر الاعتبار

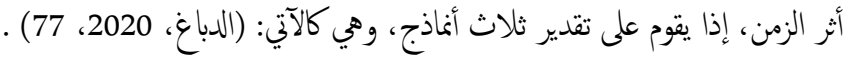

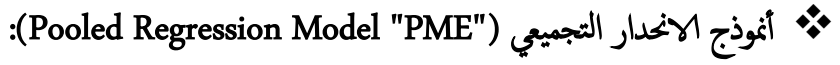


تمثل معلمات العلاقة في الآجل القصـير (Short-run Coefficients)

$$
\text { بين المتغيرات المستقلة والمتغير التابع. }
$$

(Long-run Coefficients) ) وهي

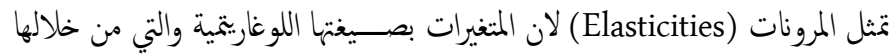
يكن التوصل إلى ما يسمى بمعادلة التكمل المشترك (أي معادلة العلاقة طوية الماتية الآجل

بين المتغير التابع والمثنغرات المستقلة).

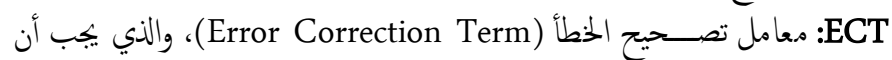

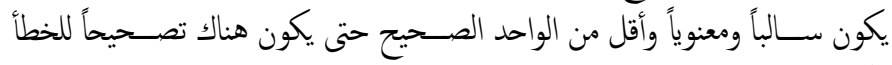
ويكون هناك إمكانية للعودة إلى الوضع التوازني.

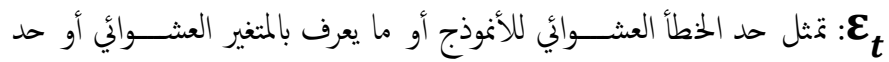

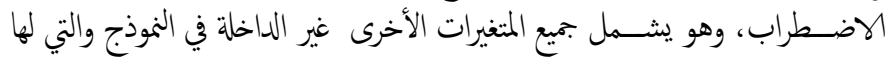
تأثير في البعد الملالي كلاستقرار السياسي وأسعار الفائدة وسعر الخص............ الخم. ومن أجل التوصـل والحصــول على نتائُ دقيقة كان لابد من اســتخدام مجموعة من

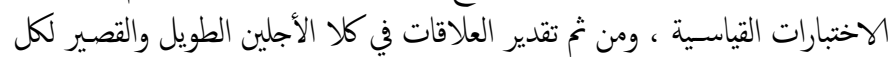
المقاطع العرضية، وعلية سيتم تطبيق ذلك وفق بمحوعة من الخطوات التالية:

المطوة الأولى: اختبار جذر الوحدة لبيانات البانل

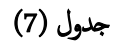

اختبار جذر الوحدة لبيانات البانل للأثموذج باستخدام (LLC)

\begin{tabular}{|c|c|c|c|c|c|c|}
\hline \multicolumn{7}{|c|}{ Levin, Lin and Chu Test } \\
\hline \multirow[b]{2}{*}{ Series } & \multicolumn{3}{|c|}{ At Level } & \multicolumn{3}{|c|}{ At First Difference } \\
\hline & Intercept & $\begin{array}{l}\text { Trend and } \\
\text { Intercept }\end{array}$ & None & Intercept & $\begin{array}{l}\text { Trend and } \\
\text { Intercept }\end{array}$ & None \\
\hline $\operatorname{Ln}(\mathrm{Y})$ & -1.88468 & -0.73417 & 0.52530 & -8.91337 & -8.15509 & -10.4379 \\
\hline prob. & $(0.2715)^{n . s}$ & $(0.2314)^{\mathrm{n.s}}$ & $(0.7003)^{n . s}$ & $(0.0000)$ & $(0.0000)$ & $(0.0000)$ \\
\hline $\operatorname{Ln}\left(X_{1}\right)$ & -3.28883 & -3.15789 & -2.10159 & $\ldots$ & $\ldots$ & $-\ldots$ \\
\hline prob. & $(0.0005)^{*}$ & $(0.0008)^{*}$ & $(0.0178)^{* *}$ & $-\ldots$ & $\ldots$ & $-\ldots$ \\
\hline $\operatorname{Ln}\left(X_{2}\right)$ & -3.34516 & -5.80424 & -0.04839 & $\ldots$ & -.- & $-\cdots$ \\
\hline prob. & $(0.0004)^{*}$ & $(0.0000)^{*}$ & $(0.4807)^{n . s}$ & $\ldots$ & $\ldots$ & $-\cdots$ \\
\hline $\operatorname{Ln}\left(X_{3}\right)$ & -3.82711 & -3.89875 & 0.38473 & $\ldots$ & $\ldots$ & $\ldots$ \\
\hline prob. & $(0.0001)^{*}$ & $(0.0000)^{*}$ & $(0.6498)^{\mathrm{n} . \mathrm{s}}$ & $-\ldots$ & $\ldots$ & $-\cdots$ \\
\hline $\operatorname{Ln}\left(X_{4}\right)$ & -4.18235 & -5.63312 & -1.11708 & $\ldots$ & $\ldots$ & $\ldots$ \\
\hline prob. & $(0.0000)^{*}$ & $(0.0000)^{*}$ & $(0.1320)^{n . s}$ & $-\ldots$ & $\ldots$ & $-\ldots$ \\
\hline $\operatorname{Ln}\left(X_{5}\right)$ & -3.72749 & -5.06991 & -0.13400 & $\ldots$ & $\ldots$ & $-\ldots$ \\
\hline
\end{tabular}

$$
\begin{aligned}
& Y_{t}=\alpha_{0}+\beta_{1} Y 1_{t-1}+\beta_{2} X 1_{t-1}+\beta_{3} X 2_{t-1}+\beta_{4} X 3_{t-1} \\
&+\beta_{5} X 4_{t-1}+\beta_{6} X 5_{t-1}+\beta_{7} X 6_{t-1} \\
&+\sum_{i=1}^{p} \gamma_{1} \Delta X 1_{t-i}+\sum_{i=1}^{p} \gamma_{2} \Delta X 2_{t-i} \\
&+\sum_{i=1}^{p} \gamma_{3} \Delta X 3_{t-i}+\sum_{i=1}^{p} \gamma_{4} \Delta X 4_{t-i} \\
&+\sum_{i=1}^{p} \gamma_{5} \Delta X 5_{t-i}+\sum_{i=1}^{p} \gamma_{6} \Delta X 6_{t-i} \\
&+\sum_{i=1}^{p} \gamma_{7} \Delta Y_{t-i}+\emptyset E C T_{t-i} \\
&\left.+\varepsilon_{t} \ldots \ldots \ldots \ldots \ldots . . .2\right)
\end{aligned}
$$

وسيتم أخذ اللوغاريتم للأساس الطبيعي لمميع متغيرات الدراسة وذلك لعدة أسباب،

$$
\text { تجنب العلاقات غير الخطية المتوقعة بين المتغيرات. }
$$

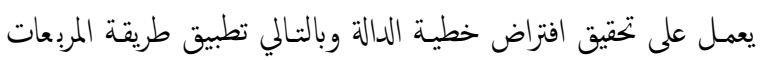

$$
\text { الصغرى الاعتيادية (OLSM) في تقدير الناذج القياسية. }
$$

$$
\text { تحقق السكون في التباينات. }
$$

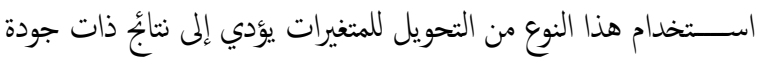

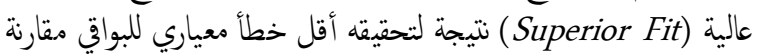

$$
\text { بالأنواع الأخرى من التحويلات. }
$$

معاملات الكخدار المقدرة ستتحول إلى مرونات ويكون تفسيرها بشكل

$$
\text { نسب مئوية. }
$$

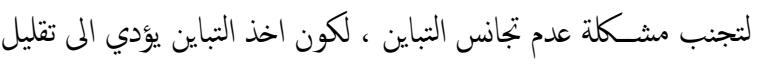

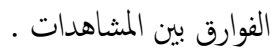

أي أن الموذج، بعد أخذ اللوغاريتم للأساس الطبيعي لجميع المنغيرات، سيكون

$$
\begin{aligned}
\operatorname{Ln}\left(Y_{t}\right)=\alpha_{0}+ & \beta_{1} \operatorname{Ln}\left(Y 1_{t-1}\right)+\beta_{2} \operatorname{Ln}\left(X 1_{t-1}\right)+\beta_{3} \operatorname{Ln}\left(X 2_{t-1}\right) \\
& +\beta_{4} \operatorname{Ln}\left(X 3_{t-1}\right)+\beta_{5} \operatorname{Ln}\left(X 4_{t-1}\right) \\
& +\beta_{6} \operatorname{Ln}\left(X 5_{t-1}\right)+\beta_{6} \operatorname{Ln}\left(X 6_{t-1}\right) \\
& +\sum_{i=1}^{p} \gamma_{1} \Delta \operatorname{Ln}\left(X 1_{t-i}\right)+\sum_{i=1}^{p} \gamma_{2} \Delta \operatorname{Ln}\left(X 2_{t-i}\right) \\
& +\sum_{i=1}^{p} \gamma_{3} \Delta \operatorname{Ln}\left(X 3_{t-i}\right)+\sum_{i=1}^{p} \gamma_{4} \Delta \operatorname{Ln}\left(X 4_{t-i}\right) \\
& +\sum_{i=1}^{p} \gamma_{5} \Delta \operatorname{Ln}\left(X 4_{t-i}\right)+\sum_{i=1}^{p} \gamma_{6} \Delta \operatorname{Ln}\left(X 5_{t-i}\right) \\
& +\sum_{i=1}^{p} \gamma_{7} \Delta \operatorname{Ln}\left(Y 1_{t-i}\right)+\emptyset E C T_{t-i} \\
& +\varepsilon_{t} \ldots \ldots \ldots \ldots \ldots . . . . . . . . .
\end{aligned}
$$

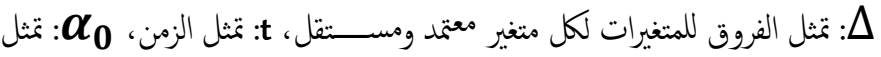
الحد الثابت. إ: تمثل عدد فتزات التأخيرات الزمنية، 
الخطوة الثانية: اختبار التكلمل المشترك (Pedroni Residual Cointegration Test)

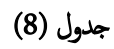

نتاجُج اختبار التكامل المشترك لبيدروني

\section{Pedroni Residual Cointegration Test}

Alternative hypothesis: common AR coefs. (within-dimension)

\begin{tabular}{|c|c|c|c|c|}
\hline & \multicolumn{2}{|c|}{$\begin{array}{c}\text { Statistic } \\
\text { Prob. }\end{array}$} & $\begin{array}{c}\text { Weighted } \\
\text { Statistic }\end{array}$ & $\underline{\text { Prob. }}$ \\
\hline Panel v-Statistic & -2.878570 & $(0.9980)^{\text {n.s }}$ & -2.952569 & $(0.9984)^{\text {n.s }}$ \\
\hline $\begin{array}{c}\text { Panel rho- } \\
\text { Statistic }\end{array}$ & 0.948710 & $(0.8286)^{\text {n.s }}$ & 0.876025 & $(0.8095)^{\text {n.s }}$ \\
\hline $\begin{array}{c}\text { Panel PP- } \\
\text { Statistic }\end{array}$ & -2.440609 & $(0.0073)^{*}$ & -3.447506 & $(0.0003)^{*}$ \\
\hline $\begin{array}{c}\text { Panel ADF- } \\
\text { Statistic }\end{array}$ & -2.465734 & $(0.0068)^{*}$ & -3.372261 & $(0.0004)^{*}$ \\
\hline
\end{tabular}

Alternative hypothesis: individual AR coefs. (between-dimension)

\begin{tabular}{|c|c|c|c|}
\hline & Statistic & Prob. & \\
\hline $\begin{array}{l}\text { Group rho- } \\
\text { Statistic }\end{array}$ & 1.763424 & $(0.9611)^{n . s}$ & \\
\hline $\begin{array}{l}\text { Group PP- } \\
\text { Statistic }\end{array}$ & -3.725279 & $(0.0001)^{*}$ & \\
\hline $\begin{array}{l}\text { Group ADF- } \\
\text { Statistic }\end{array}$ & -3.319450 & $(0.0005)^{*}$ & \\
\hline \multicolumn{4}{|c|}{ |("): مستوى معنوية 1\%، (**): مستوى معنوية 5\%، (***"): مستوى معنوية 10\%، (n.s): غير } \\
\hline
\end{tabular}

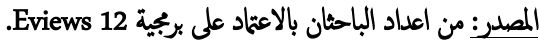

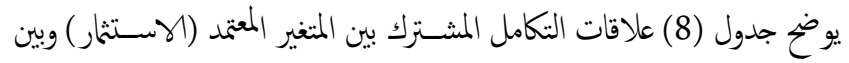

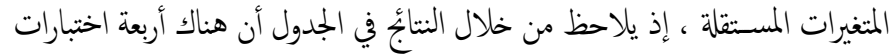

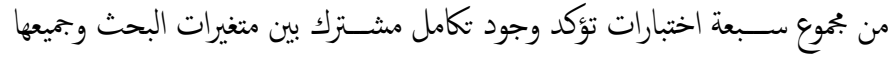
عند مســـتوى معنوية أقل من 1\% (أي وجود علاقة طويلة الآجل بين متغيرات

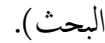

الخطوة الثالثة: تحديد فترة الإبطاء المثلى من خلال أثموذج (VAR)

جدول (9)

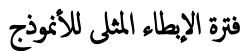

\begin{tabular}{|c|c|c|c|c|c|c|}
\hline Lag & LogL & LR & FPE & AIC & SC & HQ \\
\hline $\mathbf{0}$ & $\begin{array}{c}- \\
487.5965\end{array}$ & NA & 0.921971 & 19.78386 & 20.05154 & 19.88580 \\
\hline $\mathbf{1}$ & $\begin{array}{c}- \\
390.4362\end{array}$ & 163.2294 & 0.136931 & 17.85745 & $19.99891^{*}$ & 18.67293 \\
\hline $\mathbf{2}$ & $\begin{array}{c}- \\
338.1321\end{array}$ & 73.22571 & 0.134447 & 17.72528 & 21.74053 & 19.25431 \\
\hline $\mathbf{3}$ & $\begin{array}{c}- \\
246.8591\end{array}$ & $102.2258^{*}$ & 0.034063 & 16.03436 & 21.92339 & 18.27694 \\
\hline
\end{tabular}

\begin{tabular}{|c|c|c|c|c|c|c|}
\hline prob. & $(0.0001)^{*}$ & $(0.0000)^{*}$ & $(0.4467)^{n . s}$ & 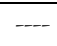 & $\ldots$ & --- \\
\hline $\operatorname{Ln}\left(X_{6}\right)$ & -481571 & -4.49809 & -0.74009 & $\ldots$ & $\ldots$ & $\ldots$ \\
\hline prob. & $(0.0000)^{*}$ & $(0.0000)^{*}$ & $(0.2296)^{n . s}$ & $\cdots$ & $\ldots$ & $-\cdots$ \\
\hline غير | غ غ & ) $\%$ & "**t & 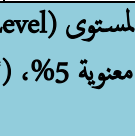 & مستق & إلمعن أر & 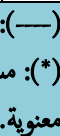 \\
\hline
\end{tabular}

المصدر: من إعداد الباحثان بالاعتاد برجية 12 معنة

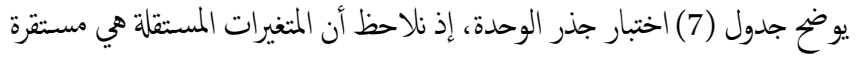

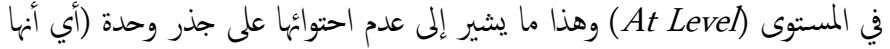

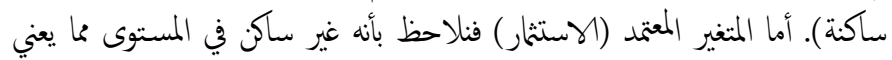

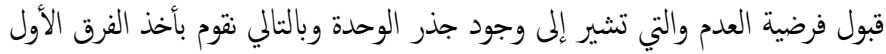

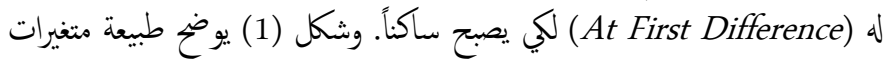
الأنموذج اتجاهها خلال مدة البحث.

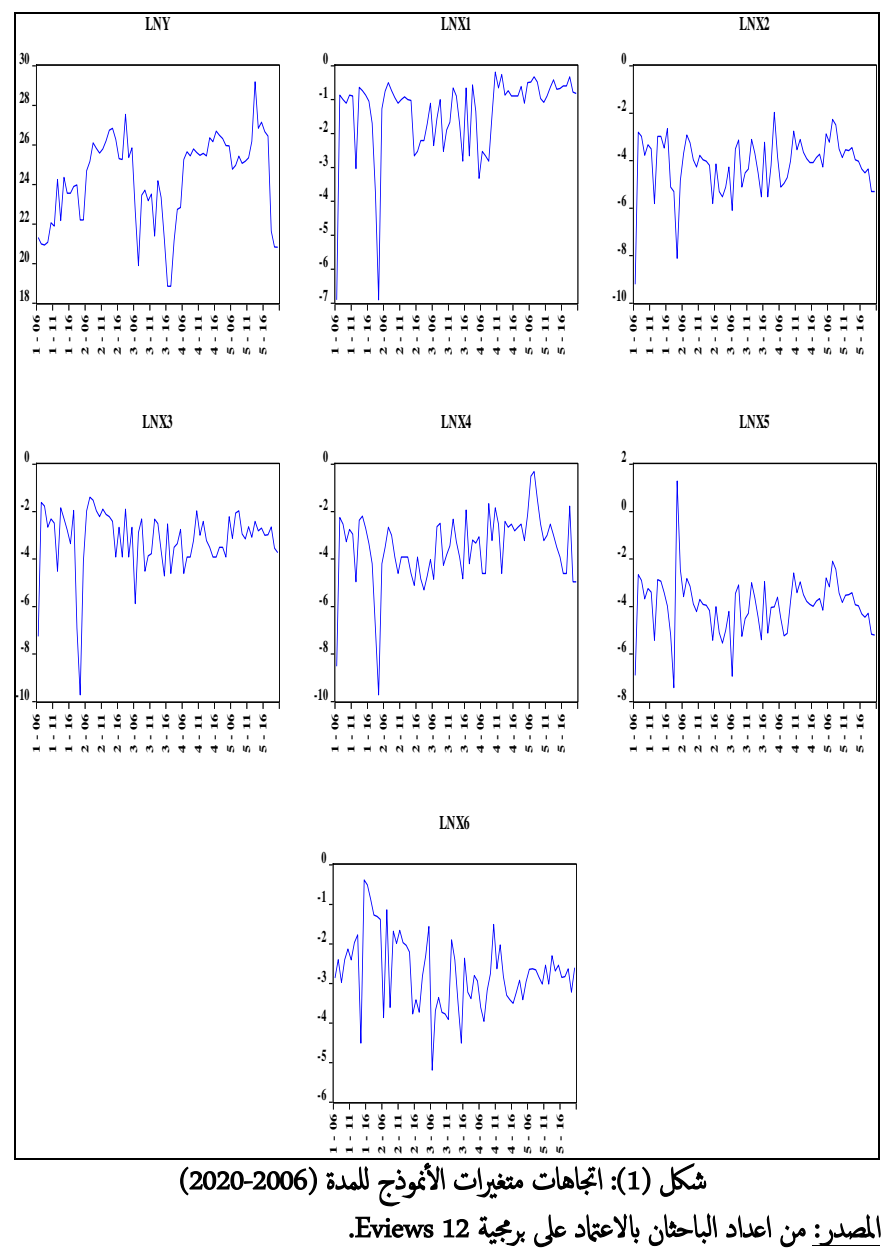




\begin{tabular}{|c|c|c|c|c|}
\hline $\mathrm{D}(\mathrm{LX} 5)$ & 2.798389 & 2.936190 & 0.953068 & $(0.3501)^{n . s}$ \\
\hline $\mathrm{D}(\mathrm{LX6})$ & -0.635630 & 0.223008 & -2.850253 & $(0.0088)^{*}$ \\
\hline C & 10.40840 & 5.042814 & 2.064006 & 0.0500 \\
\hline @TREND & 0.235268 & 0.334846 & 0.702614 & 0.4891 \\
\hline \multicolumn{5}{|c|}{ ("): مستوى معنوية 1\%، (**): مستوى معنوية 5\%، (***): مستوى معنوية 10\%، (n.s): } \\
\hline
\end{tabular}

المصدر: من اعداد الباحثان بالاعتاد على برجية 12 Eviews.

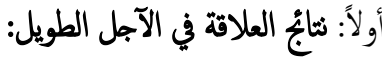

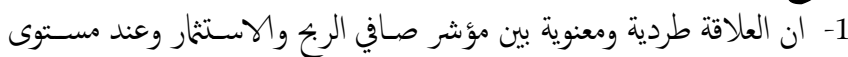

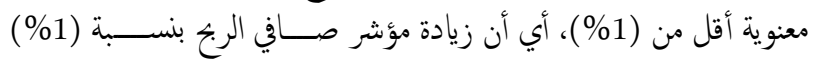
سيؤدي إلى زيادة الاستثمار بنسبة (6.90\%).

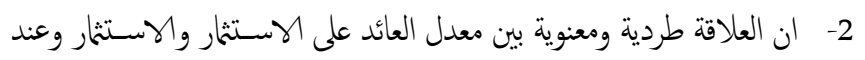

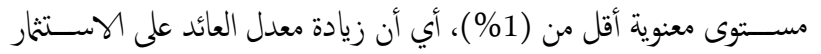

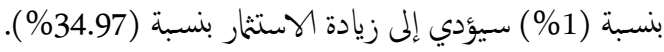

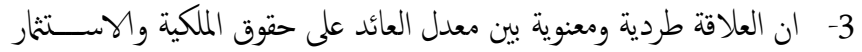

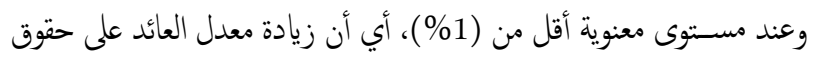
الملكية بنسبة (1\%) سيؤدي إلى زيادة الاستثمار بنسبة (15.83\%).

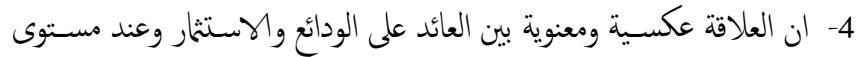

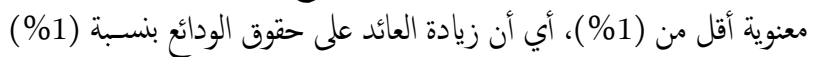

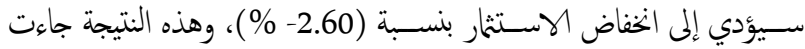
مخالفة لمنطوق النظرية الاقتصادية. 5- ان العلاقة عكسـية ومعنوية بين معدل العائد على الأموال المتاحة والاستـثنار

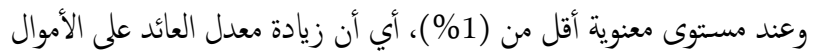

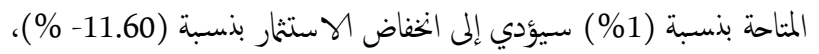
وهذه النتيجة لا تنسجم ومنطوق النظرية الاقتصادية.

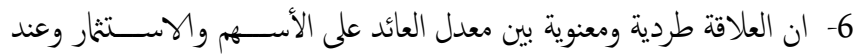

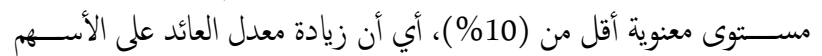

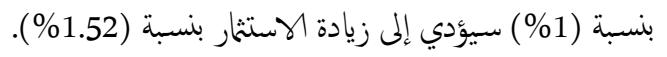

\section{ثانياً: نتابُ العلاقة في الآجل القصير:}

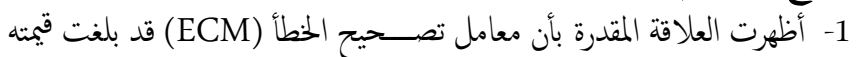

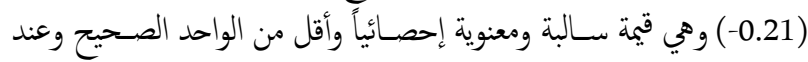

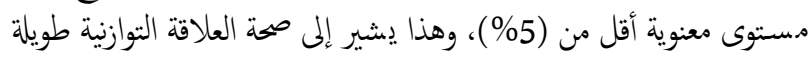

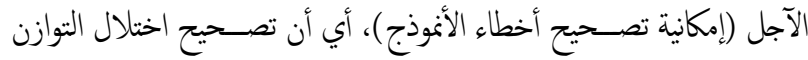

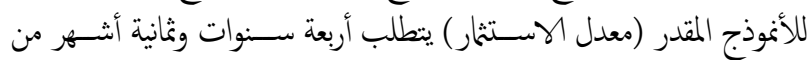
أجل العودة إلى الوضع التوازني.

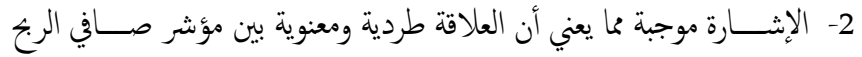

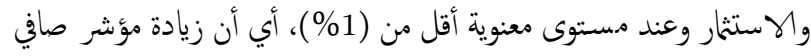
الربح بنسبة (1\%) سيؤدي إلى زيادة الاستثمر بنسبة (1.48\%).

\begin{tabular}{|c|c|c|c|c|c|c|}
\hline $\mathbf{4}$ & $\begin{array}{c}- \\
175.6780\end{array}$ & 59.79212 & 0.028338 & 15.14712 & 22.90993 & 18.10324 \\
\hline $\mathbf{5}$ & $\begin{array}{c}- \\
69.86821\end{array}$ & 59.25347 & $0.012735^{*}$ & $12.87473^{*}$ & 22.51132 & $16.54440^{*}$ \\
\hline $\mathbf{6}$ & $\begin{array}{c}- \\
487.5965\end{array}$ & $\mathrm{NA}$ & 0.921971 & 19.78386 & 20.05154 & 19.88580 \\
\hline $\mathbf{7}$ & $\begin{array}{c}- \\
390.4362\end{array}$ & 163.2294 & 0.136931 & 17.85745 & $19.99891^{*}$ & 18.67293 \\
\hline $\mathbf{8}$ & $\begin{array}{c}- \\
338.1321\end{array}$ & 73.22571 & 0.134447 & 17.72528 & 21.74053 & 19.25431 \\
\hline
\end{tabular}

المصدر: من اعداد الباحثان بالاعتاد على برجية 12 Eviews.

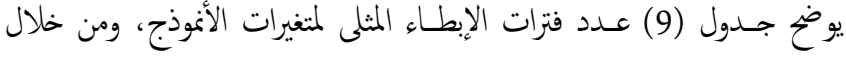

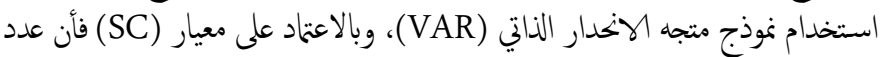
فترات الإبطاء المثلى التي تخلص الأثموذج من مشكلة الارتباط الذاتي للبواقي هي (1).

الخطوة الرابعة: تقدير وتفسير ثناجُ الآجل الطويل والقصير ومعلمة تصحيح الخطأ باستخدام مقدرات وسط المجموعة المدبجة (PMG) في بيثة نموذج (ARDL)

جدول (10)

نتانج الآجل الطويل والقصير ومعلمة تصحيح الخطاً

Method: Panel ARDL-PMG

Dependent Variable: $\mathrm{D}[\operatorname{Ln}(\mathrm{Y})]$

\begin{tabular}{|c|c|c|c|c|}
\multicolumn{5}{|c|}{ Dynamic egressors (1 lag, automatic): $\operatorname{Ln}(\mathrm{X} 1) \operatorname{Ln}(\mathrm{X} 2) \operatorname{Ln}(\mathrm{X} 3) \operatorname{Ln}(\mathrm{X} 4)$} \\
\multicolumn{5}{c|}{$\operatorname{Ln}(\mathrm{X} 5) \operatorname{Ln}(\mathrm{X} 6)$} \\
\hline Variable & Coefficient & Std. Error & $\mathrm{t}-$ Statistic & Prob. \\
\hline $\operatorname{Ln}(\mathrm{X} 1)$ & 6.901057 & 1.423800 & 4.846928 & $(\mathbf{0 . 0 0 0 1})^{*}$ \\
\hline $\operatorname{Ln}(\mathrm{X} 2)$ & 34.96548 & 4.474888 & 7.813711 & $(\mathbf{0 . 0 0 0 0})^{*}$ \\
\hline $\operatorname{Ln}(\mathrm{X} 3)$ & 15.83369 & 2.526820 & 6.266253 & $(\mathbf{0 . 0 0 0 0})^{*}$ \\
\hline $\operatorname{Ln}(\mathrm{X} 4)$ & -2.601668 & 0.279814 & -9.297857 & $(\mathbf{0 . 0 0 0 0 )}$ \\
\hline $\operatorname{Ln}(\mathrm{X} 5)$ & -11.60234 & 1.646637 & -7.046082 & $(\mathbf{0 . 0 0 0 0})^{*}$ \\
\hline $\operatorname{Ln}(\mathrm{X} 6)$ & 1.523991 & 0.883237 & 1.725461 & $(\mathbf{0 . 0 9 7 3})^{* * *}$ \\
\hline
\end{tabular}

\begin{tabular}{|c|c|c|c|c|}
\hline \multicolumn{5}{|c|}{ Short-Run Equation } \\
\hline COINTEQ01 & -0.209464 & 0.118415 & -1.768899 & $(\mathbf{0 . 0 4 3 2})^{* *}$ \\
\hline D(LX1) & 1.478351 & 0.974383 & 1.517217 & $(\mathbf{0 . 0 0 5 6})^{*}$ \\
\hline D(LX2) & -7.444484 & 4.616834 & -1.612465 & $\left(\mathbf{0 . 1 1 9 9 ) ^ { \mathbf { n } . }}\right.$ \\
\hline D(LX3) & 2.888829 & 1.749348 & 1.651375 & $\mathbf{( 0 . 1 1 1 7}^{\mathbf{n . s}}$ \\
\hline D(LX4) & 1.314343 & 1.375421 & 0.955593 & $(\mathbf{0 . 3 4 8 8})^{\mathbf{n . s}}$ \\
\hline
\end{tabular}


زيادة معدل العائد على الأموال المتاحة بنســــة (1\%) ســـيؤدي إلى زيادة

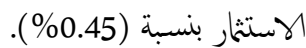

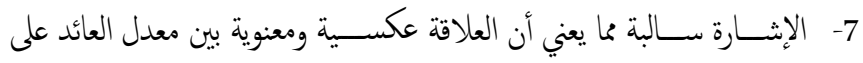

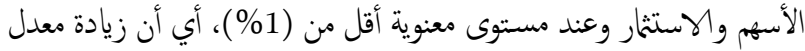

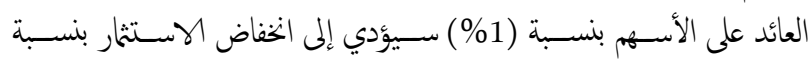

. $\%$-0.10)

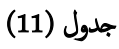

تانج تقدير العلاقة قصيرة الآجل في المصرف الاستثماري العراقي

\begin{tabular}{|c|c|c|c|c|}
\hline Variable & Coefficient & Std. Error & t-Statistic & Prob. $^{*}$ \\
\hline COINTEQ01 & -0.160129 & 0.001402 & -114.1988 & 0.0000 \\
\hline D(LNX1) & 1.864998 & 0.249467 & 7.475944 & 0.0050 \\
\hline D(LNX2) & -4.999234 & 0.991942 & -5.039848 & 0.0151 \\
\hline D(LNX3) & -0.474403 & 0.089455 & -5.303247 & 0.0131 \\
\hline D(LNX4) & 6.697930 & 1.080898 & 6.196633 & 0.0085 \\
\hline D(LNX5) & 0.446044 & 0.034677 & 12.86295 & 0.0010 \\
\hline D(LNX6) & -0.102159 & 0.011158 & -9.155314 & 0.0028 \\
\hline C & 10.31412 & 4.059622 & 2.540660 & 0.0846 \\
\hline @TREND & -0.215061 & 0.002692 & -79.87941 & 0.0000 \\
\hline
\end{tabular}

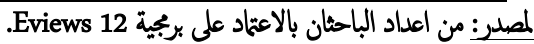

ثانياً: مصرف بغداد: Bank of Baghdad

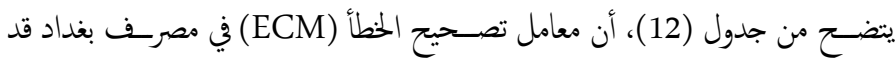

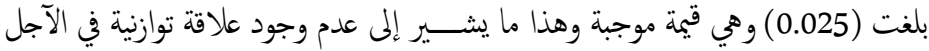

إحالقصير بين متغيرات الدراسة باتجاه علاقة توازنية طويلة الآجل.

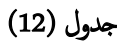

نثاجُ تقدير العلاقة قصيرة الآجل في مصرف بغداد

\begin{tabular}{|c|c|c|c|c|}
\hline Variable & Coefficient & Std. Error & t-Statistic & Prob. $^{*}$ \\
\hline COINTEQ01 & 0.025057 & 0.000154 & 162.5646 & 0.0000 \\
\hline D(LNX1) & 1.146683 & 0.036597 & 31.33288 & 0.0001 \\
\hline D(LNX2) & -3.138959 & 1.247495 & -2.516210 & 0.0865 \\
\hline D(LNX3) & 1.114869 & 0.016904 & 65.95459 & 0.0000 \\
\hline D(LNX4) & 0.461621 & 0.098010 & 4.709931 & 0.0181 \\
\hline D(LNX5) & 1.862396 & 1.772264 & 1.050857 & 0.3705 \\
\hline D(LNX6) & -0.197976 & 0.003173 & -62.40024 & 0.0000 \\
\hline C & -1.052566 & 0.667113 & -1.577794 & 0.2127 \\
\hline @TREND & -0.077644 & 0.000277 & -280.6051 & 0.0000 \\
\hline
\end{tabular}

المصدر: من اعداد الباحثان بالاعثاد على برجية 12 .Eviews.

ثالثأ: المصرف الأهلي العراقي: National Bank of Baghdad

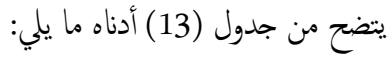

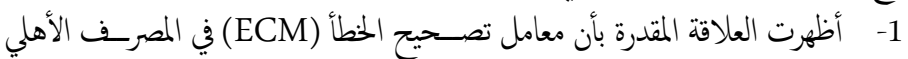

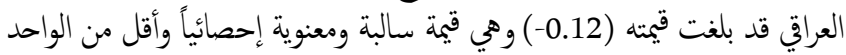

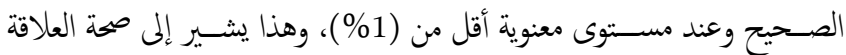

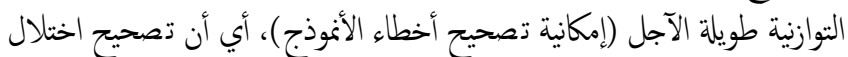

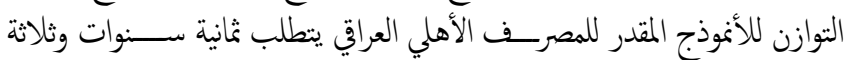

$$
\text { أشهر من أجل العودة إلى الوضع التوازني. }
$$

3- الإنثـارة سـالبة مما يعني أن العلاقة عكسـية بين معدل العائد على الاسـتثار

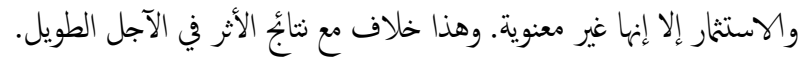

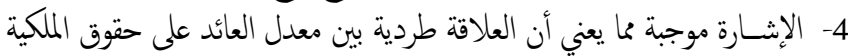

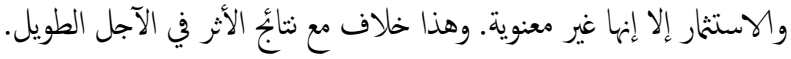

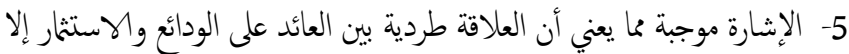

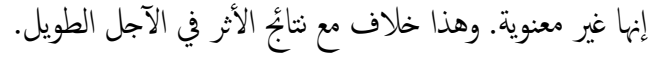

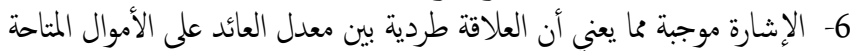

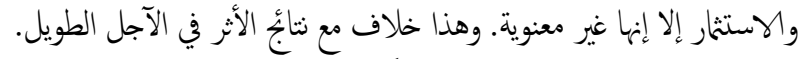

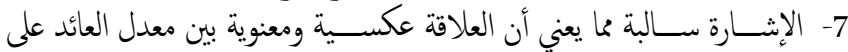

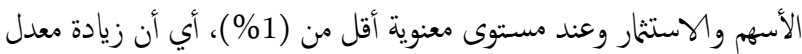

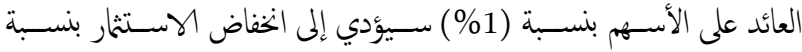

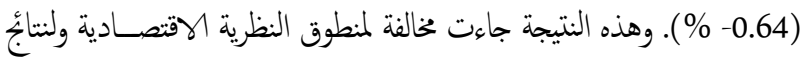

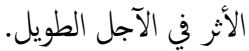

\section{الخطوة الخامسة: تقدير العلاقات قصيرة الآجل على مستوى المصرف الواحد}

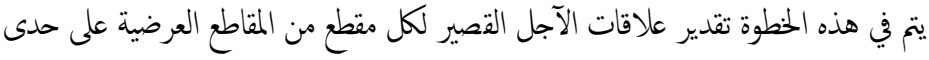
(أي بالنسبة للمصرف الواحد)، وكالآتي:

\section{أولاً: مصرف الاستثمار العراقي: Investment Bank of Iraq}

يتضح من جدول (11) أدناه ما يلي:

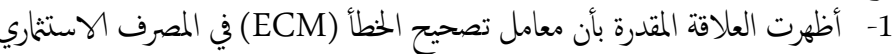

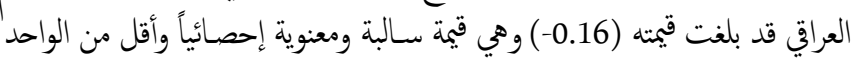

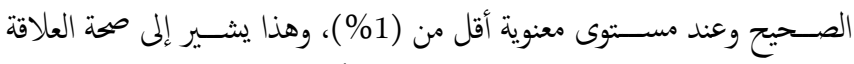

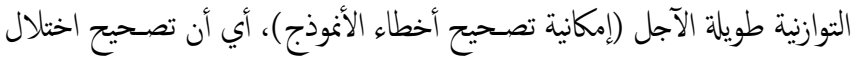

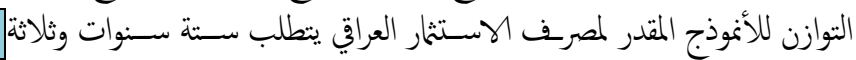
أشهر من أجل العودة إلى الوضع التوازني.

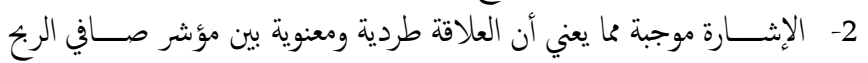

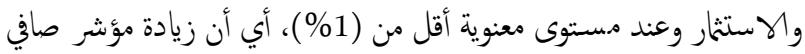

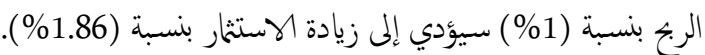

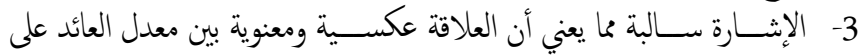

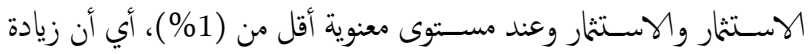

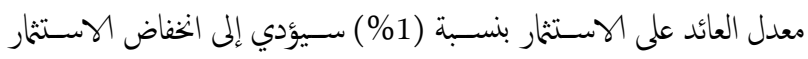

بنسبة (4.999- \% \% وهذا لاينسجم مع منطوق النظرية الاقتصادية .

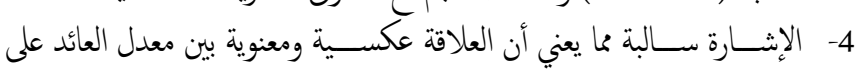

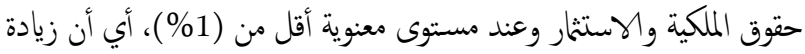

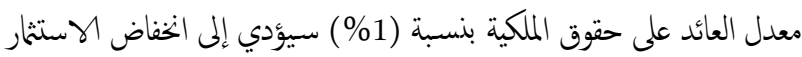
بنسبة (0.47- \% \%). 5- الإثـــارة موجبة مما يعني أن العلاقة طردية ومعنوية بين العائد على الودائع

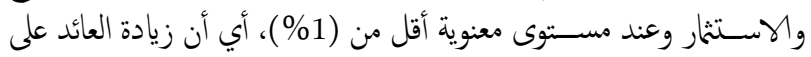

الودائع بنسبة (1\%) سيؤدي إلى زيادة الاستثمار بنسبة (6.698\%).

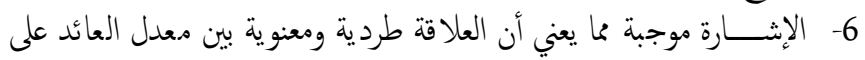

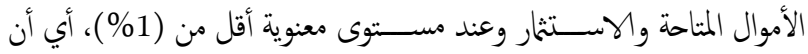


معدل العائد على الأسهم بنسبة (1\%) سيؤدي إلى انخفاض الاستثار

بنسبة (0.59- (\%).

جدول (14)

تانجُ تقدير العلاقة قصيرة الآجل في المصرف التجاري العراقي

\begin{tabular}{|c|c|c|c|c|}
\hline Variable & Coefficient & Std. Error & t-Statistic & Prob. ${ }^{*}$ \\
\hline COINTEQ01 & -0.126399 & 0.004204 & -30.06425 & 0.0001 \\
\hline D(LNX1) & 1.501324 & 0.290771 & 5.163253 & 0.0141 \\
\hline D(LNX2) & -1.206199 & 1.717741 & -0.702201 & 0.5331 \\
\hline D(LNX3) & 0.666318 & 0.475414 & 1.401553 & 0.2556 \\
\hline D(LNX4) & 0.126296 & 0.014662 & 8.614145 & 0.0033 \\
\hline D(LNX5) & -0.189998 & 0.184743 & -1.028446 & 0.3794 \\
\hline D(LNX6) & -0.591411 & 0.073128 & -8.087329 & 0.0040 \\
\hline C & 6.617115 & 11.29882 & 0.585647 & 0.5993 \\
\hline @TREND & 0.016008 & 0.000809 & 19.79869 & 0.0003 \\
\hline
\end{tabular}

المصدر: من اعداد الباحثان بالاعثاد على برجية 12 .Eviews.

خامساً: مصرف المنصور للاستثمار: Mansour Bank for Investment يتضح من جدول (15) ما يأتي:

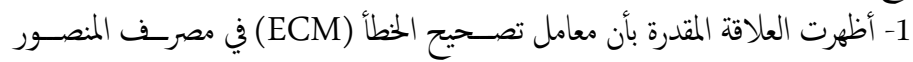

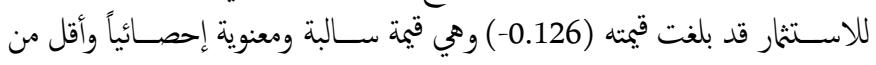

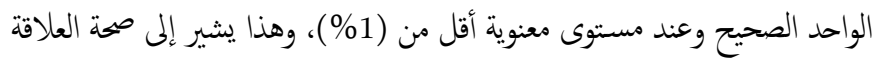

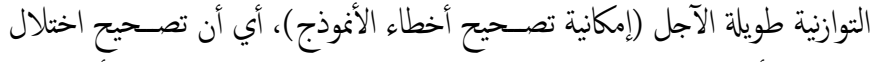

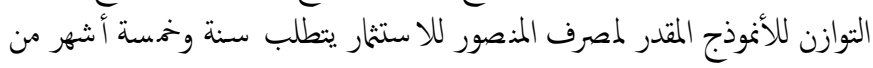
أجل العودة إلى الوضع التوازني.

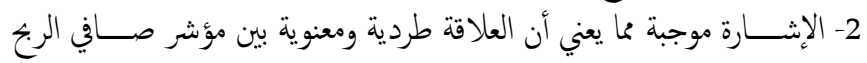

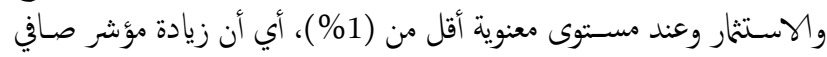

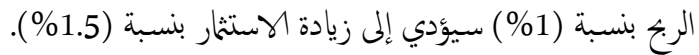

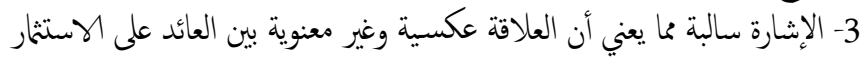
والاستثمار.

4- الإثـارة موجبة مما يعني أن العلاقة طردية ومعنوية بين العائد على حقوق الملكية

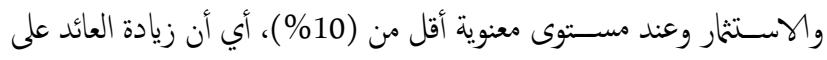

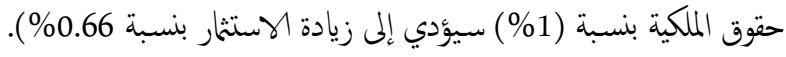

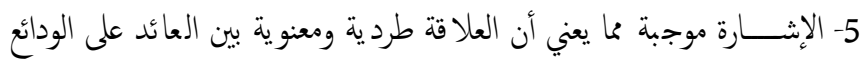

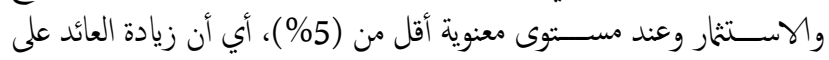

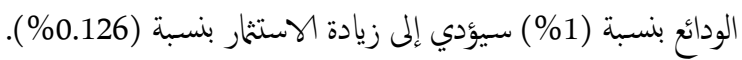

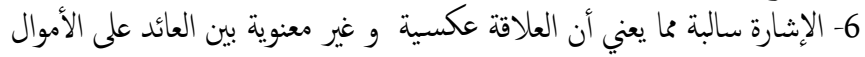

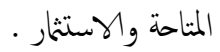
7- الإنشارة سالبة ما يعني أن العلاقة عكسية ومعنوية بين معدل العائد على الأسهم

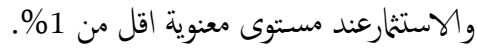

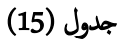

تانجّ تقدير العلاقة قصيرة الآجل في مصرف المنصور للاستثار

\begin{tabular}{|c|c|c|c|c|}
\hline Variable & Coefficient & Std. Error & t-Statistic & Prob. $^{*}$ \\
\hline COINTEQ1 & -0.126399 & 0.004204 & -30.06425 & 0.0001 \\
\hline D(LNX1) & 1.501324 & 0.290771 & 5.163253 & 0.0141 \\
\hline
\end{tabular}

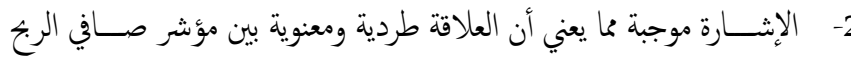

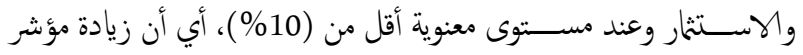

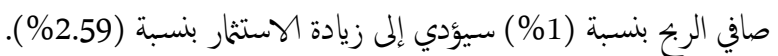

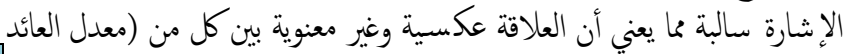
$-3$

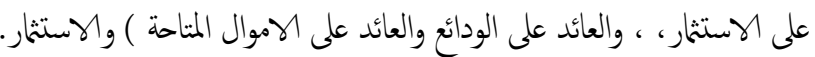

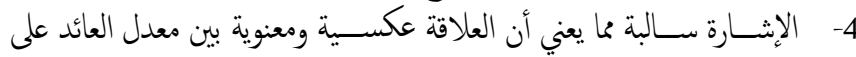

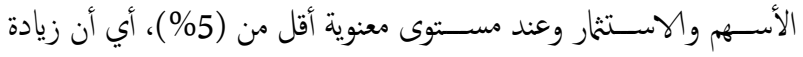

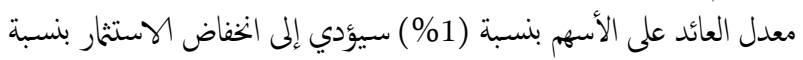
.(\% -1.17)

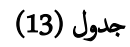

تناجُ تقدير العلاقة قصيرة الآجل في المصرف الأهلي العراقي

\begin{tabular}{|c|c|c|c|c|}
\hline Variable & Coefficient & Std. Error & t-Statistic & Prob. * \\
\hline COINTEQ01 & -0.120167 & 0.001951 & -61.58628 & 0.0000 \\
\hline D(LNX1) & 2.586313 & 0.956051 & 2.705205 & 0.0735 \\
\hline D(LNX2) & -2.138329 & 1.109077 & -1.928026 & 0.1495 \\
\hline D(LNX3) & 3.855391 & 2.644394 & 1.457948 & 0.2409 \\
\hline D(LNX4) & -1.107686 & 1.519040 & -0.729202 & 0.5187 \\
\hline D(LNX5) & -2.351359 & 5.917205 & -0.397377 & 0.7177 \\
\hline D(LNX6) & -1.166820 & 0.253619 & -4.600671 & 0.0193 \\
\hline C & 7.011326 & 4.859811 & 1.442716 & 0.2448 \\
\hline @TREND & -0.113424 & 0.005181 & -21.89189 & 0.0002 \\
\hline
\end{tabular}

المصدر: من اعداد الباحثان بالاعثاد على برجية 12 .Eviews.

\section{رابعاً: المصرف التجاري العراقي: Commercial Bank of Iraq} يتضح من جدول (14) ما يأتي:

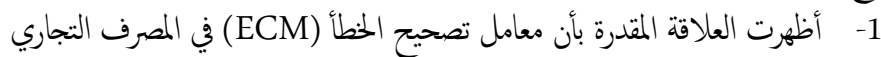

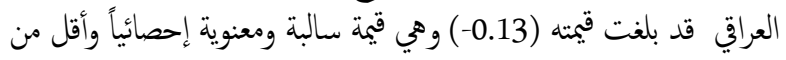

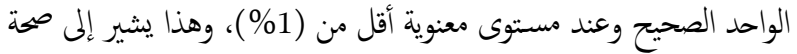

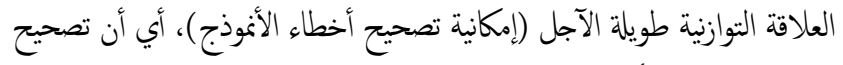

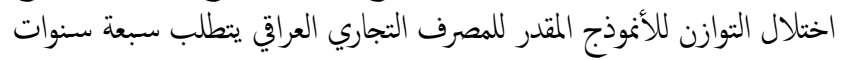

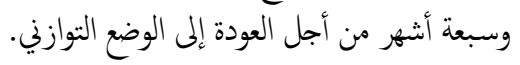

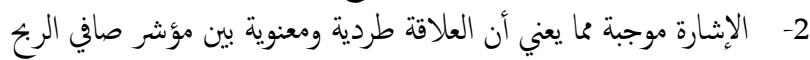

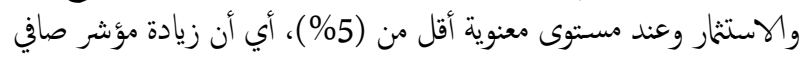

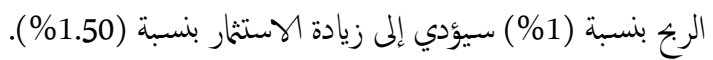

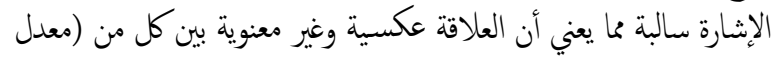
$-3$

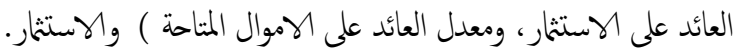

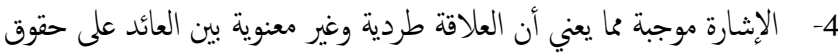
الملكية والاستثمار. 5- الإثشارة موجبة مما يعني أن العلاقة طردية ومعنوية بين العائد على الودائع

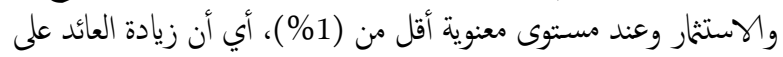

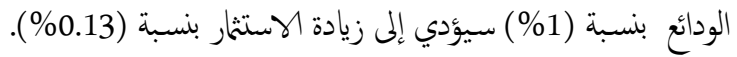

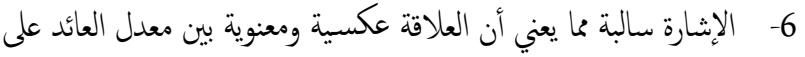

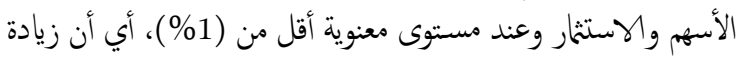


اختبار التوزيع الطبيعي للبواقي: Normality Distribution of Test

Residuals

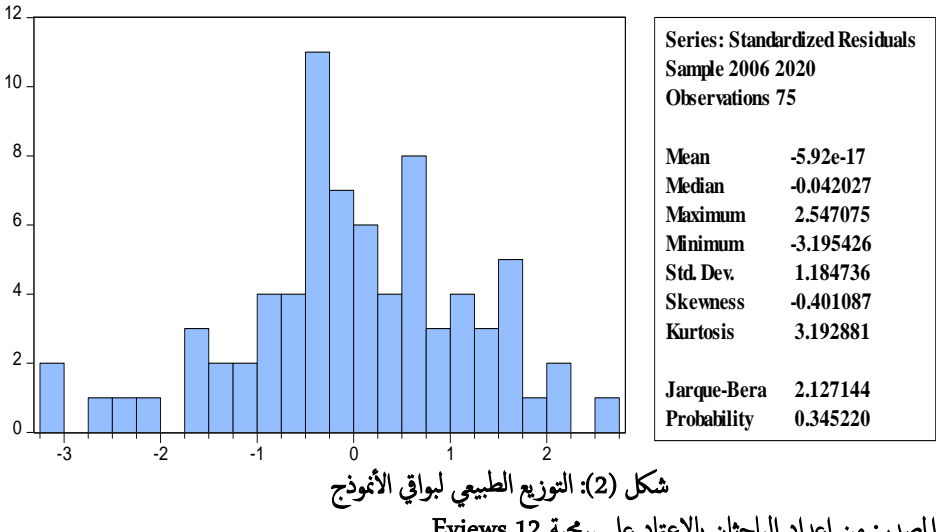

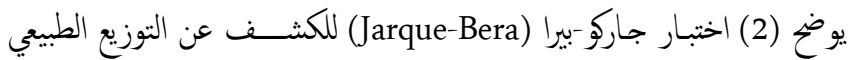
لبواقي الأثموذج المقدر، إذ نلاحظ أن قيمة الاحتمالية للاختبار قد بد بلغت (2.127)

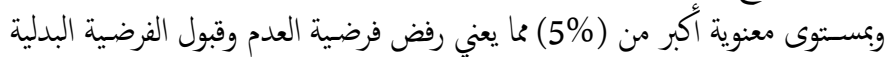

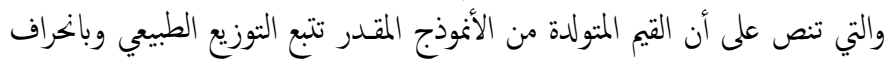

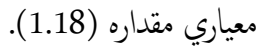

-4 - اختبار التعدد الخطي بين المتغيرات المستقلة: Multicollinearity Test جدول (18)

اختبار التعدد الخطي بين المتغيرات المستقلة في الأثوذج (8)

\begin{tabular}{|c|c|c|c|}
\hline \multirow{2}{*}{ Variable } & Coefficient & Uncentered & Centered \\
\cline { 2 - 4 } & Variance & VIF & VIF \\
\hline LX1 & 0.179323 & 9.588098 & 4.150266 \\
\hline LX2 & 0.302741 & 87.23515 & 6.513918 \\
\hline LX3 & 0.122664 & 22.88957 & 3.441194 \\
\hline LX4 & 0.121417 & 27.89915 & 4.144282 \\
\hline LX5 & 0.067600 & 17.92720 & 1.508656 \\
\hline LX6 & 0.099097 & 12.73037 & 1.277723 \\
\hline C & 1.852607 & 28.99836 & NA \\
\hline
\end{tabular}

المصدر: من اعداد الباحثان بالاعتاد على برجية 12 تصنية

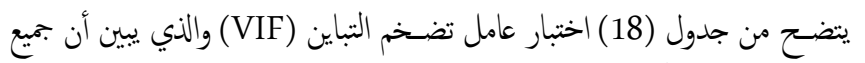

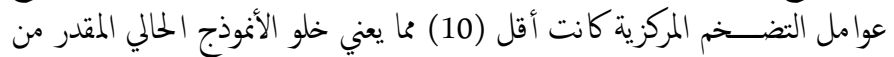
مشكة التداخل الخطي المتعدد بين متغيراته المستقلة.

الاستنثاجات والمقتزحات

اولا : الاستناجات

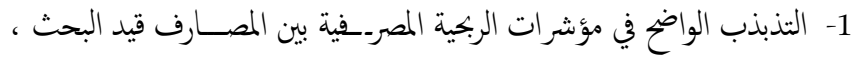

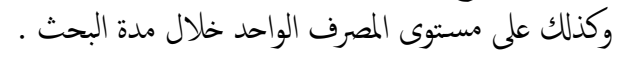

\begin{tabular}{|c|c|c|c|c|}
\hline $\mathrm{D}(\mathrm{LNX}$ 2) & -1.206199 & 1.717741 & -0.702201 & 0.5331 \\
\hline $\mathrm{D}$ (LNX3) & 0.666318 & 0.475414 & 1.401553 & 0.2556 \\
\hline $\mathrm{D}$ (LNX4) & 0.126296 & 0.014662 & 8.614145 & 0.0033 \\
\hline $\mathrm{D}$ (LNX5) & -0.189998 & 0.184743 & -1.028446 & 0.3794 \\
\hline $\mathrm{D}$ (LNX6) & -0.591411 & 0.073128 & -8.087329 & 0.0040 \\
\hline $\mathrm{C}$ & 6.617115 & 11.29882 & 0.585647 & 0.5993 \\
\hline @TREND & 0.016008 & 0.000809 & 19.79869 & 0.0003 \\
\hline
\end{tabular}

المصلر: من اعداد الباحثان بالاعتاد على برجية 12 .Eviews.

الخطوة السادسة: الاختبارات التشخيصية للموذج المقدر 1- اختبار خلو الأثموذج من مشكلة الارتباط اللذاتي: Autocorrelation Test

جدول (16) اختبار الارتباط الناتي لبواقي الأموذج

\begin{tabular}{|c|c|c|c|}
\hline Test & Statistic & d.f. & Prob. \\
\hline Breusch-Pagan LM & 8.521051 & 10 & 0.5781 \\
\hline Pesaran scaled LM & -0.330703 & & 0.7409 \\
\hline Bias-corrected scaled LM & -0.523011 & & 0.6010 \\
\hline Pesaran CD & 1.025100 & & 0.3053 \\
\hline
\end{tabular}

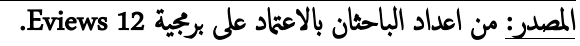

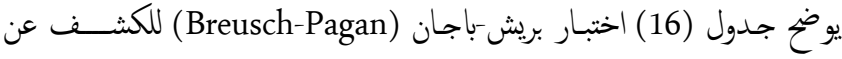

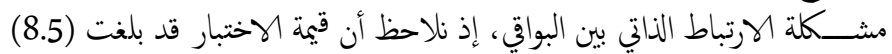

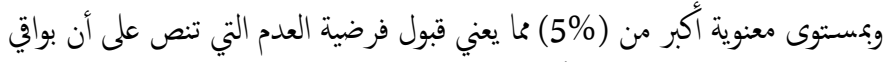

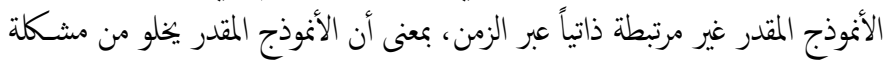
الارتباط الذاتي.

2- اختبار خلو الأثموذج من مشكلة عدم تجانس الثباين: Heteroskedasticity Test

جدول (17)

اختبار مشكلة عدم تجانس الثباين لبواتي الأموذج

\begin{tabular}{|c|c|c|c|}
\hline \multicolumn{4}{|c|}{ Heteroskedasticity Test: Breusch-Pagan-Godfrey } \\
\hline F-statistic & 0.993664 & Prob. F(6,68) & 0.4367 \\
\hline Obs*R-squared & 6.045658 & Prob. Chi-Square(6) & 0.4181 \\
\hline Scaled explained SS & 4.416561 & Prob. Chi-Square(6) & 0.6205 \\
\hline
\end{tabular}

المصدر: من اعداد الباحثان بالاعتاد على برجية 12 (6views.

يوضح جدول (17) اختبار بريش-باجان-كودفري (Breusch-Pagan-Godfrey)

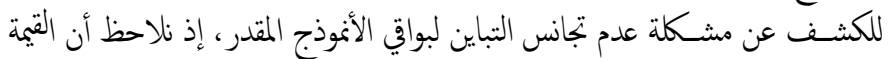

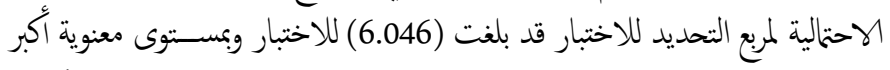

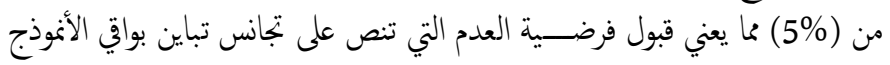
المقدر (بكعنى عدم وجود مشكلة تجانس التباين). 


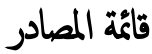

\section{اولا: المصادر باللغة العربية}

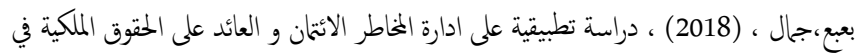

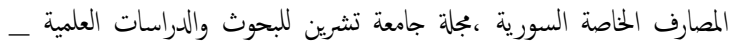

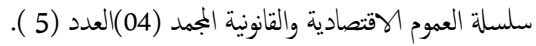

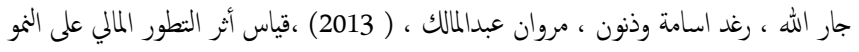

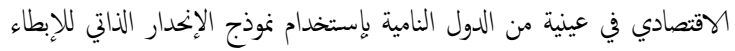

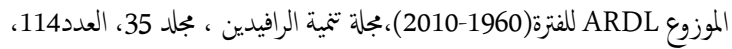

$$
\text { جامعة الموصل، كلية الإدارة و الاقتصاد ، الموصل، العراق. }
$$

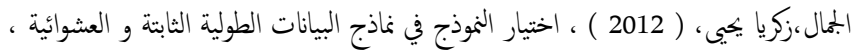

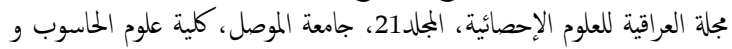

$$
\text { الرياضيات، الموصل، العراق. }
$$

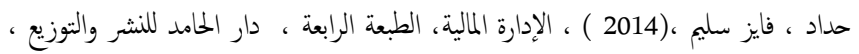

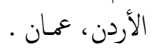

حجادة،طارق عبد العالي( 2001 ) ، تثييم أداء البنوك التجارية "تحليل العائد والخخاطر، الدار

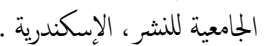

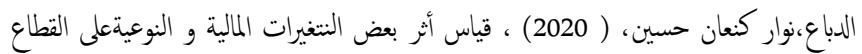

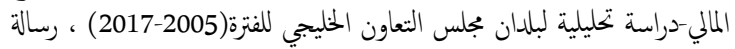

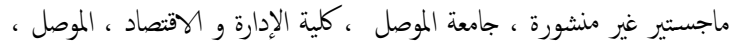
العراق.

السيفو،وليد اسلاعيل وفيصل ، فتاحشلوف ،وصائب ، جواد ابراهيم، (ل 2006 ) ، سمشاكل

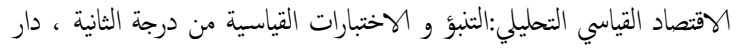

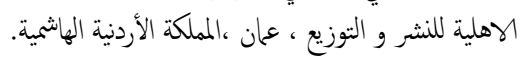

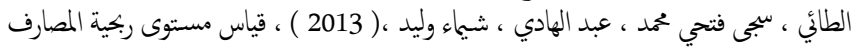

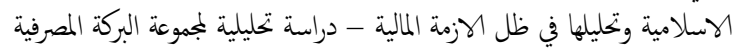

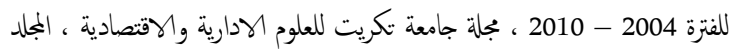

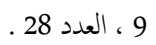

-عطية، عبدالسلام ، (2016) ، أثر الصادرات النفطية على المنو الاقتصادي_راسة قياسية لدول

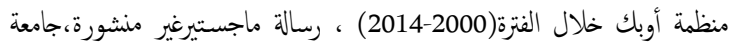

$$
\text { قاصدي مرباح،كلية العلوم الاقتصادية و علوم التسيير، ،ورقالة، الجزائير. }
$$

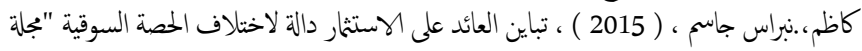

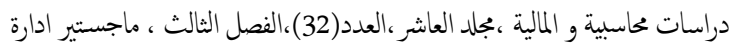

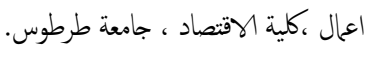

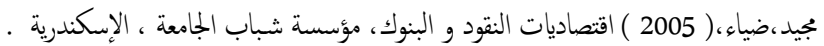

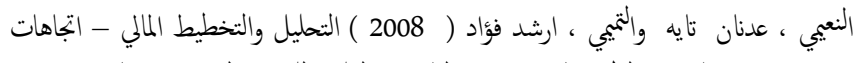

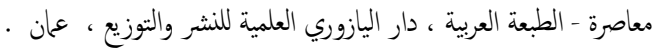

ثانيا : المصادر باللغة الانكليزية

Gujarati,Damodar,2003,Basic Econometrics, The Mc Graw-Hill Companies,Inc,New York,USA.

Timothy Neal, 2014,Panel cointegration analysis with xtpedroni, The Stata Journal, University of New South Wales,Sydney,Australia.

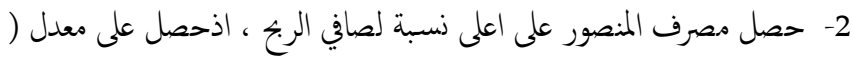

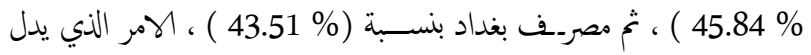

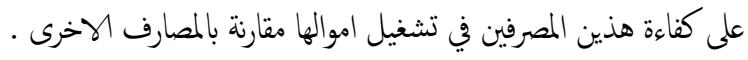

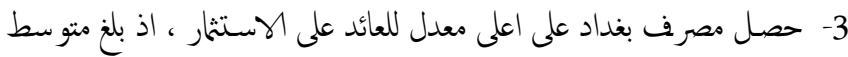

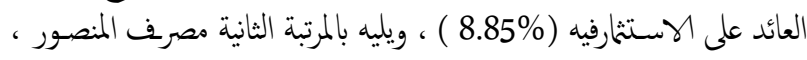

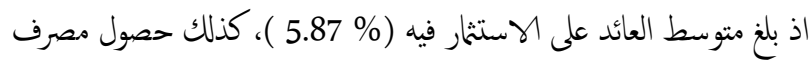

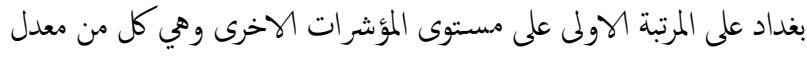

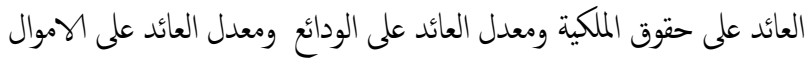

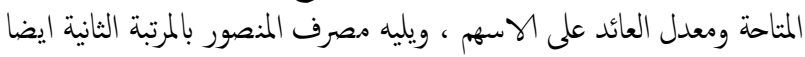

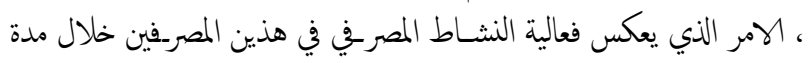

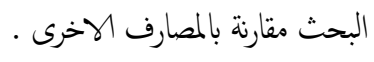

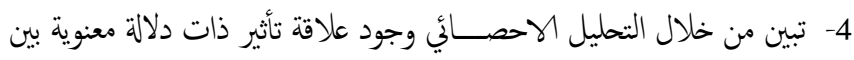

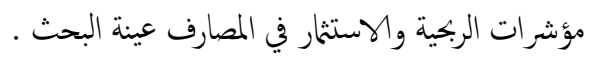

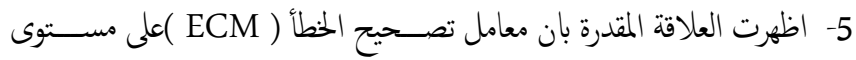

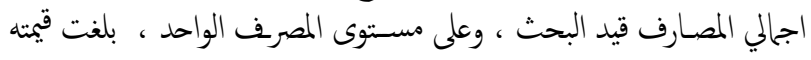

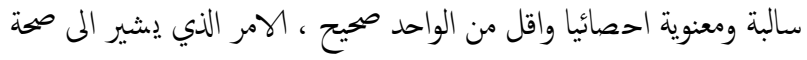

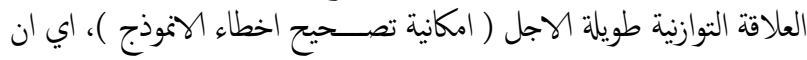

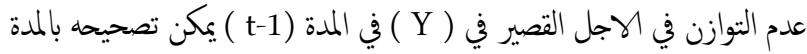

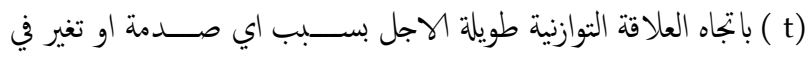

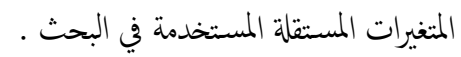

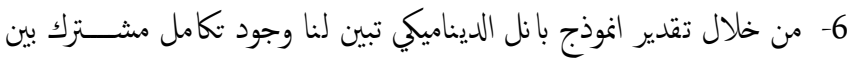

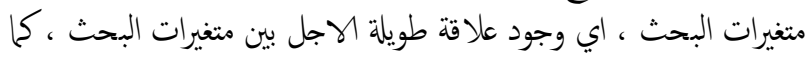

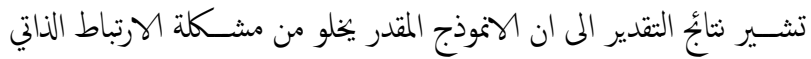

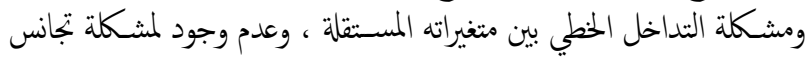
التباين

ثانيا : المتترحات

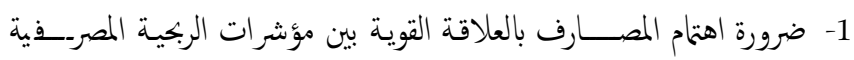

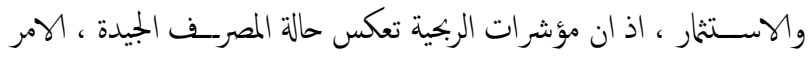

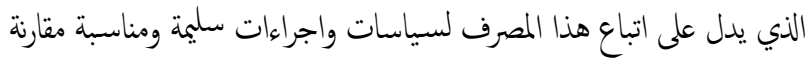
مع المصارف الاخرى .

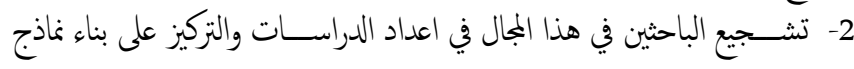

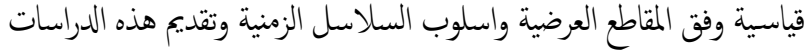

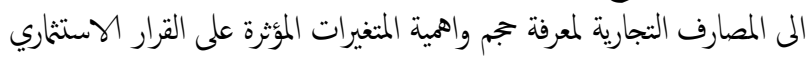

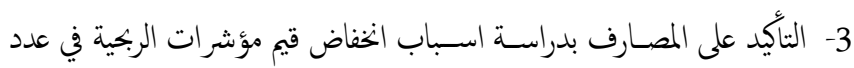

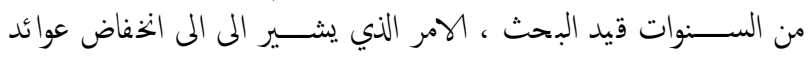

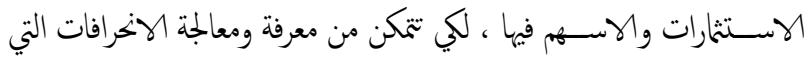
حصلت خلال هذه السنوات والعمل على تحقيق افضل العوائد . 